University of Louisville

ThinkIR: The University of Louisville's Institutional Repository

College of Arts \& Sciences Senior Honors

Theses

College of Arts \& Sciences

$5-2014$

\title{
Women's activism and social networks in post-genocide Rwanda.
}

Michelle Cecelia Marie Fox

University of Louisville

Follow this and additional works at: https://ir.library.louisville.edu/honors

Part of the Social and Cultural Anthropology Commons

\section{Recommended Citation}

Fox, Michelle Cecelia Marie, "Women's activism and social networks in post-genocide Rwanda." (2014). College of Arts \& Sciences Senior Honors Theses. Paper 89.

http://doi.org/10.18297/honors/89

This Senior Honors Thesis is brought to you for free and open access by the College of Arts \& Sciences at ThinkIR: The University of Louisville's Institutional Repository. It has been accepted for inclusion in College of Arts \& Sciences Senior Honors Theses by an authorized administrator of ThinkIR: The University of Louisville's Institutional Repository. This title appears here courtesy of the author, who has retained all other copyrights. For more information, please contact thinkir@louisville.edu. 
Women's Activism and Social Networks in Post-Genocide Rwanda

\section{By}

Michelle Cecelia Marie Fox

Submitted In Partial Fulfillment of The Requirements For Graduation Summa Cum Laude and For Graduation With Honors From The Departments of Anthropology and Sociology

University of Louisville

May, 2014 


\section{UNIVERSITY OF LOUISVILLE}

\section{FACULTY OF ARTS AND SCIENCES}

\section{This Thesis Was Presented}

By

Michelle C M Fox

It was defended on

March 17, 2014

And Approved on $\frac{19 \text { Manch } 2014}{\text { (Date) }}$ by

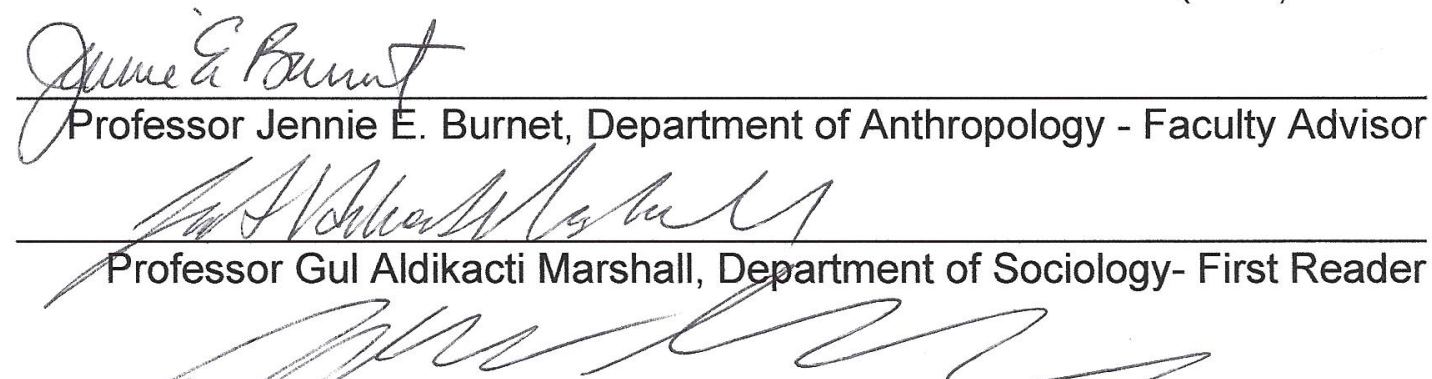

Professor John Gibson, Department of Philosophy-Second Reader 


\section{Abstract}

Following the 1994 genocide the social networks of many Rwandan women changed. The loss of kin, particularly men, left many women needing new sources of social and material support. Beginning in the early 1990s the international development and aid community recognized the need to integrate gender analysis in their work and began to focus on women's activism and efforts to improve the position of women in the supposed developing world. Using social network data and structured interview data gathered in Rwanda in June and July 2013 from 30 women, this study attempts to answer the question: Do women who were adults before the 1994 genocide rely more heavily on membership in women's organizations for support than women who became adults after the genocide? The results of this study conclude, in addition to women's organizations, religious affiliations account for a significant portion of support in the social networks of Rwandan women. Because support commonly comes from non-secular women's organizations as well as mixed gender religious organizations international aid providers should reframe their provisions of aid to best serve both segments of society and any overlap. 


\section{Acknowledgements}

I would like to thank Dr. Jennie E. Burnet, my professor and mentor, for her continued encouragement, guidance and confidence in my abilities as a student and researcher. I am grateful for the many opportunities she has helped me pursue and the knowledge I have gained as a result. This thesis would not have been possible without the support of the Undergraduate Research Opportunity Program, The Office of the Executive Vice President of Research and Innovation, and the National Science Foundation Cultural Anthropology Program. Special thanks to the Professors of the University of Louisville Anthropology and Sociology Departments. I would like to thank Dr. Gul Marshall and Dr. John Gibson for taking time to review my thesis. I would like to thank Joanna Thompson for her assistance in gathering the data I have analyzed for my thesis. Additionally, I would like to thank her for her friendship and support both abroad and in the United States. I would like to extend my gratitude to my friend Madalyn DuPlessis for reading many drafts and providing encouraging words. To our friends and translators, Germaine Umuraza, Pascaline Umulisa and Carine Ruremesha, I extend my gratitude for your guidance and patience. Special thanks to Pro-Femme Twese Hamwe for your hospitality, interest and support, without which this research would not have been possible. I would like to acknowledge my family for their unconditional love, confidence and faith in me through all my studies and life. Finally, I would like to thank the women who volunteered for interviews and the inhabitants of Kigali, Rwanda for their kindness. 


\section{Table of Contents}

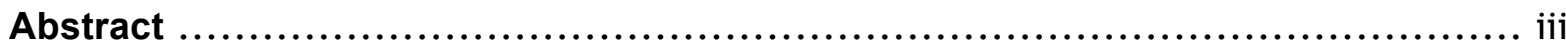

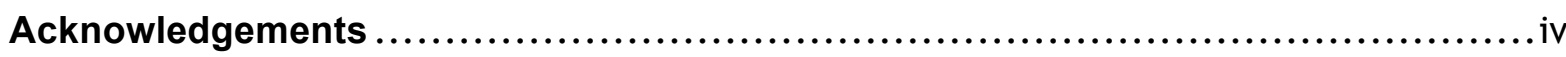

List of Figures .................................................................vi

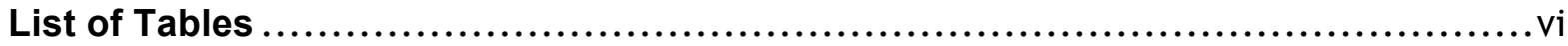

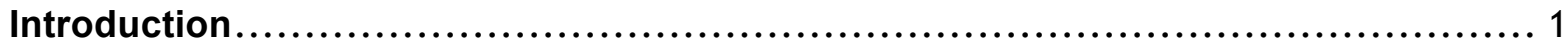

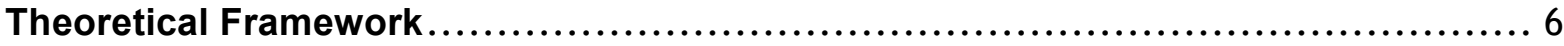

Agency and Desire .......................................................... 6

Global Feminism ............................................................... 7

Historical Context ............................................................. 9

Genocide ....................................................................... 9

Ethnicity and Gender in Post-Genocide Rwanda .................................. 12

Insecurity for Women in Post-Genocide Rwanda.................................... 14

Rwandan Women's Organizations ............................................. 17

Social Network Analysis ...................................................... 20

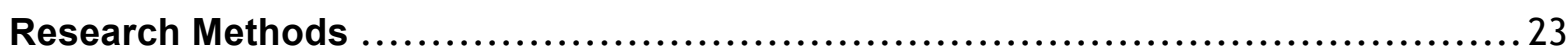

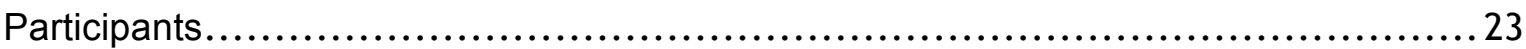

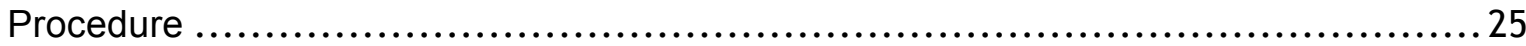

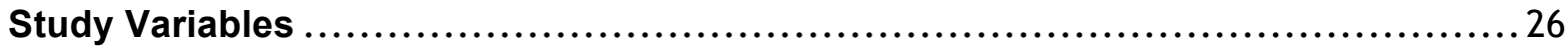

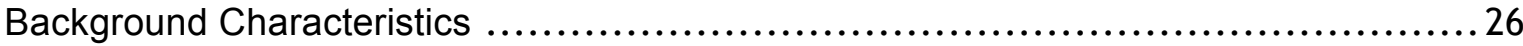

Network Elicitation ......................................................... 26

Network Composition and Relationship Characteristics .............................. 27

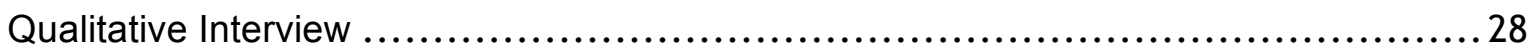

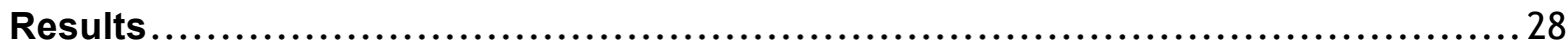

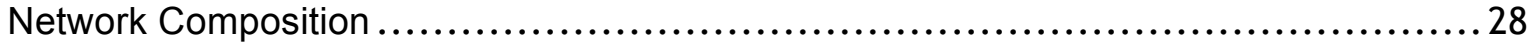

Alters' Involvement in Women's Organizations ................................... 30

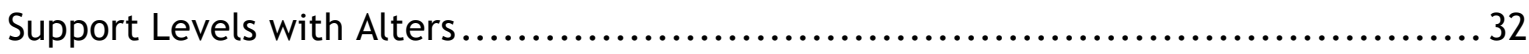

Religious Affiliations of Alters and Participants ................................... 33

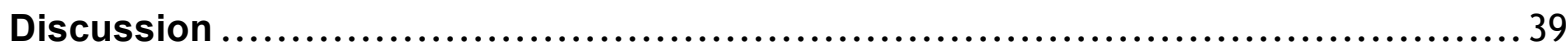

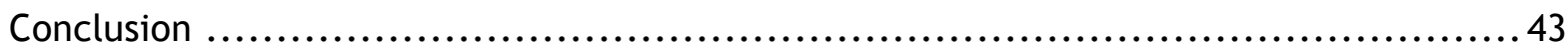

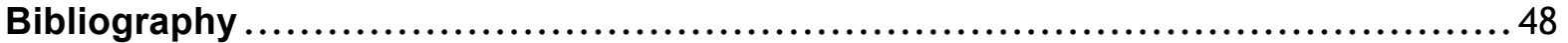




\section{List of Figures}

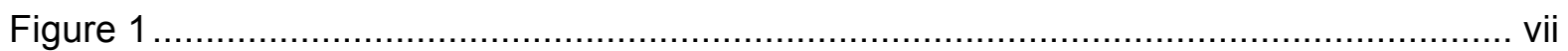

Figure 2

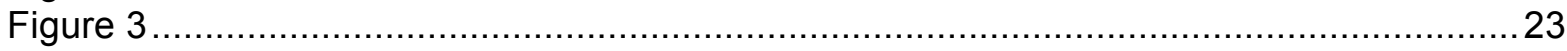

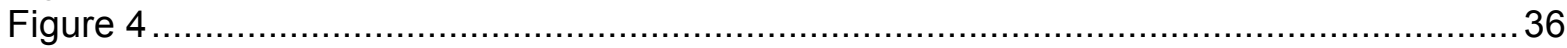

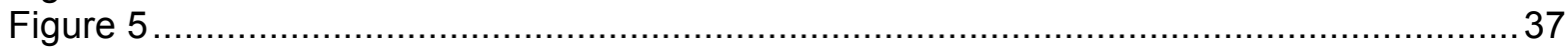

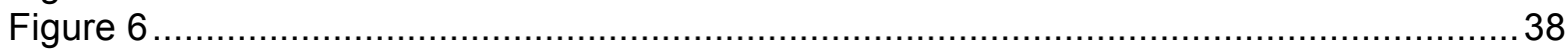

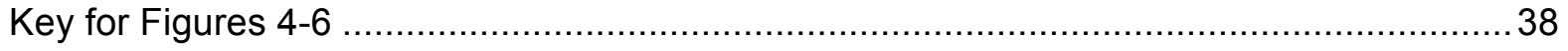

\section{List of Tables}

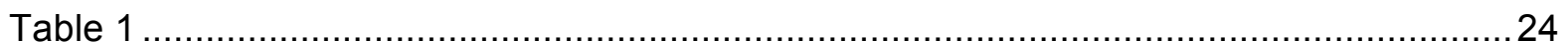

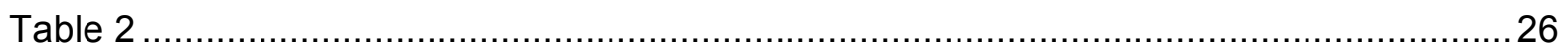

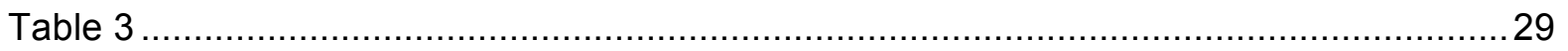

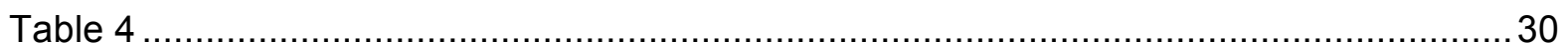

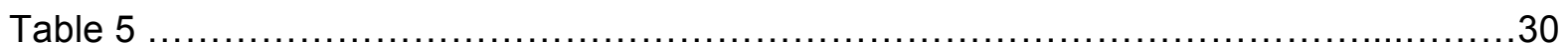

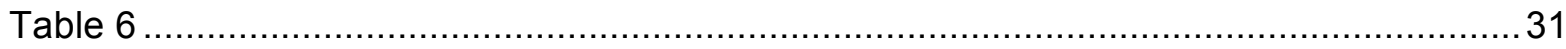

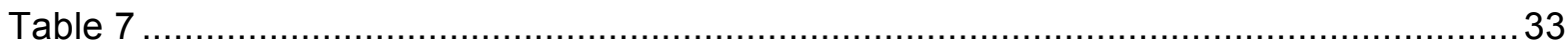

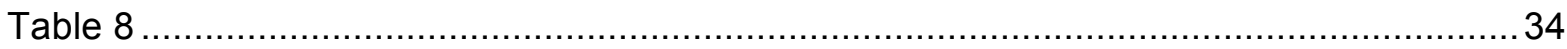

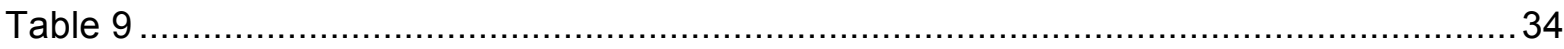

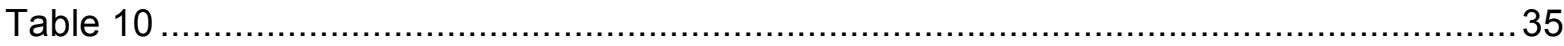

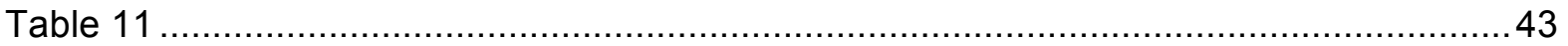


Figure 1

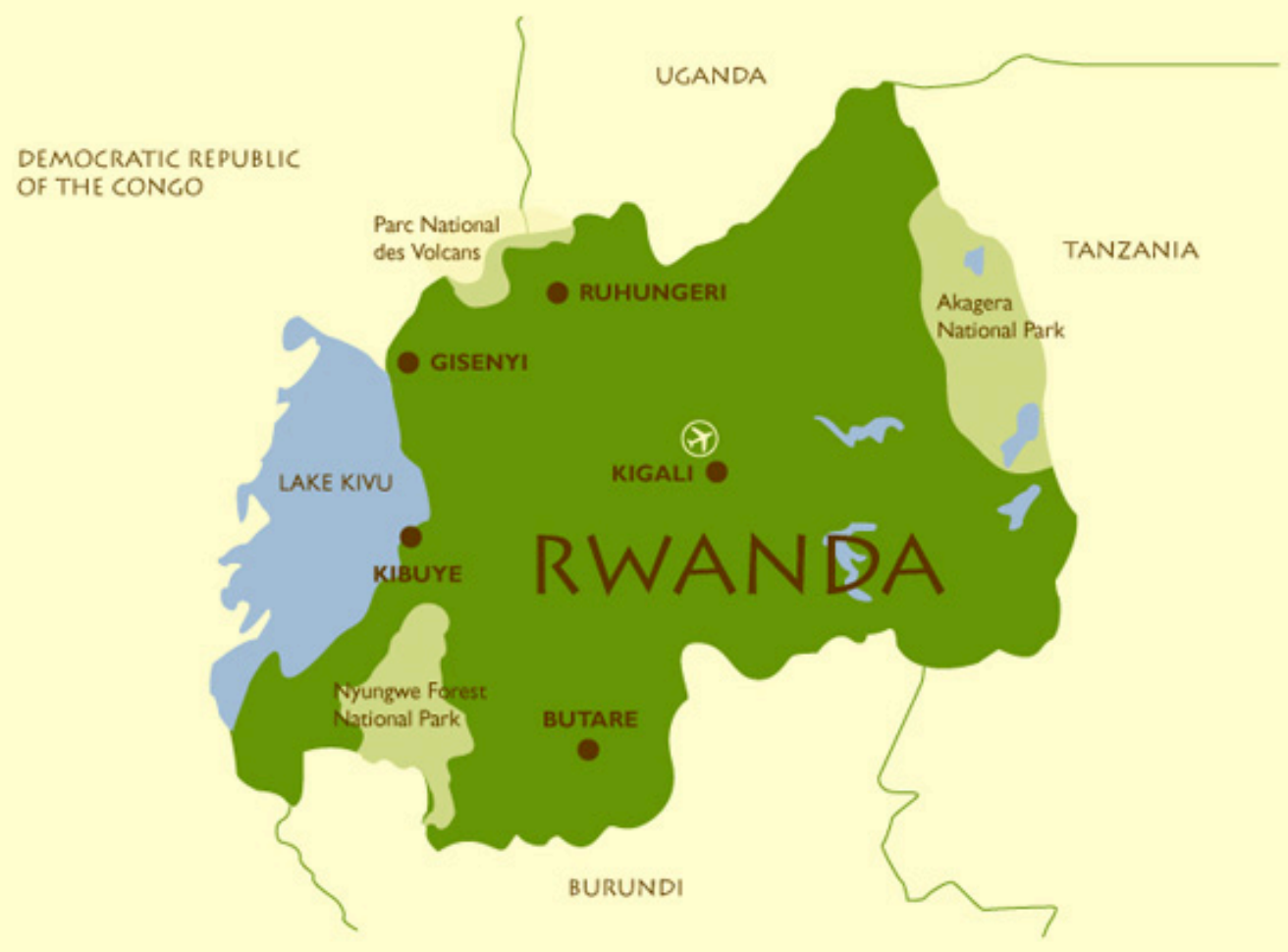

http://www.imagineafrica.co.uk/Rwanda/Rwanda_Map 


\section{Introduction}

Hunger, poverty, displacement and physical victimization impact men and women during instances of widespread violence. However, men and women experience victimization and depravation during conflict differently (Kumar 2001:7). Similarly women experience life differently depending on their location in time and space. Women do not form a homogenous group globally. The specific realities of womanhood are defined contextually and are deeply entrenched in locatedness, culture, economy, policy and other characteristics of specific societies. In many, if not all, societies women occupy subject positions lending them to constraints not enacted upon male members of the same society. In Michel Foucault's view the context in which a subject resides determines the meaning of the position the subject occupies (2010[1972]). Many anthropologists, (Burnet, Hafez, Butler, Lemarchand, Uvin) sociologists and (Gilman, Hill-Collins, Kleinman) other theorists (Rich) have expanded on Foucault's ideas. One such Anthropologist, Sherine Hafez (2011) states "subject making cannot be understood as a continuous process within a single paradigm" but rather "subject making should be considered as deeply embedded in wider, complex, and intricate social and historical processes" (5). Hafez (2011) suggests that the social positions of individuals depend heavily on the physical and temporal space in which they are located. Therefore, the social location of women depends both on their identity as a woman and on their physical location. However, the form constraints take depends on the physical and historical location of the place in which they occur (Rich 1976:286287).

Armed conflict situations heavily impact gendered behaviors. The implications of armed conflict on women constitute three primary categories: social and psychological, economic, and 
political (Kumar 2011:7). During armed conflict men are more likely to be killed in combat or direct violence while women remain more vulnerable to indirect effects of combat (Ormhaug 2009:22). Female dependency on male kin for social and financial support exemplifies an ordinary constraint placed on women which armed conflict situations serve to exacerbate. The removal of men from social networks as a result of conflict, often due to death, prisoner status or fleeing violence, thrusts women into situations of destitution and desperation, and dwindles their social networks. Armed conflicts continue to impact the lives of women even after the cessation of large scale organized violence through persistent economic and social strain.

Twenty years later Rwanda continues to experience long-term impacts of the genocide, in which approximately 500,000 to 800,000 Rwandans, mostly of Tutsi ethnicity lost their lives (Lemarchand 2009:69; Des Forges 1999). In the aftermath of the genocide, international attention and financial support increased to help the country recover from the genocide (Newbury and Baldwin 2001:27). Much of this assistance specifically targeted women. Since 1994, the social location of women within Rwanda shifted dramatically due to the loss of kin, international attention to women's rights, higher proportions of female government officials and advocates, and general development efforts in the country. Many men were killed in the violence, fled for refuge in other countries, or were arrested as a result of their actions during the genocide. In societies, such as Rwanda, where female inheritance, property and social action occur through male kin, indirect effects of conflict wreak havoc. Female agency experienced pressure and drastic shifts as a result of the genocide.

Following the installation of the Rwandan Patriotic Front (RPF) controlled government at the end of 1994; the number of female public officials increased. However, the "Rwandan state has become increasingly authoritarian under the guise of 'democratization'” (Burnet 2008:363). 
Increased representation of women in government positions introduced a paradox: as the representation of women in the government went up, their ability to impact public policy declined (Burnet 2008:363). Women who are not included in the mainstream political system currently seek interactional and institutional level agency through participation in women's organizations. The decisions on the part of the government likely resulted from international donors' recent fetishization of the social positions of women globally.

High global interest in the social positions of women created positive and negative outcomes. The intentions and outcomes of international aid and the social status of women globally remain complex. To a certain degree the new focus on women in development constructs another power dynamic that impacts the lives of people targeted for development (Escobar 1995:187). Development aid often operates on an imperialistic mindset wherein the culture, social structure and attributes of Western societies hold status as the goals of development, and other nations receive aid intended to create progress, but also to Westernize. The impacts of developmental agencies are numerous, but for the purposes of this analysis the focus will be on their support of women's groups and political involvement.

Development agencies primarily seeking economic development and westernization of Rwanda were present within Rwanda prior to the genocide. The actions of these agencies had significant influence on the global status of the country as well as internal power dynamics. According to the international community, Rwanda was progressing towards status as a developed nation prior to the 1994 genocide. While development personnel remained in the country, they did nothing to prevent the genocide and impending tragedy (Uvin 1998:2). Following the conclusion of the genocide, Rwanda was still considered a well developing nation by the international community; however, violence was still a threat in the Great Lakes region 
(Uvin 1998:1). The connection of development personnel to the 1994 genocide leads to a series of important questions: "what was the role of development, as conceived and implemented in Rwanda, in the unfolding of the processes that led to the horrible events of April 1994" (Uvin 1998:2). And subsequently, how does the tainted status of externally implemented development agencies impact the ethics of their continued involvement within the country? Are the current actions of development agencies dangerous to Rwandans? Could they possibly influence the beginning of another tragedy? The above questions heavily influence the argument of this paper; however, they are not explicitly addressed in depth. Since Burnet (2012), Lemarchand (2009), Uvin (1998) and (Escobar 1995) and addressed these question in depth, I focused specifically on women's social networks and their implications for development efforts.

Rwandan women's organizations dependence on international financing compromises their autonomy. The resurgence and rise of women's organizations in Rwanda resulted in part from heightened international support (Newbury et al 2001:99). International aid commonly takes the form of money or physical resources (Newbury et al 2001:99). Women's organizations depend on international aid for their existence, leading to their questionable autonomy (Kumar 2001:206-211). The dynamic of power and dependency created by the financial attachment serves to further entrench Western domination, and enact a new form of imperialism. However, the heightened political involvement of women creates space in which to pursue the advancement of women and gender equality. Additionally, many women's organizations provide resources and support to vulnerable groups, such as widows. The social and practical good of women's organizations coupled with their neither fully positive nor negative relationship with international aid makes their position within Rwanda an important area of research. 
This research aims to address whether Rwandan women's organizations fill the social void left by loss of male kin for older Rwandan women. All individuals undergo experiences in their lifetimes wherein they need social support in the forms of: friendship, counsel, confidants, spiritual aid, emotional support and assistance with resources such as food, finances and shelter. Largely as a result of the 1994 genocide drastic shifts in women's social location occurred. As a result of shifts in social location, the avenues through which women receive and give social support changed. This shift occurred between the generation that grew into adulthood prior to the 1994 genocide and the generation that grew into adulthood after its conclusion. For the purposes of this project, women who would have been adults during the 1994 genocide as well as women who were children or born after the conclusion of the genocide were interviewed for a comparative study. I primarily aim to answer the question: Are women within the older cohort more dependent on their social network connections through Rwandan women's organizations than their counterparts in the younger cohort? To answer this question I interviewed women who are members of women's organizations. I hypothesize women in the older cohort depend more heavily on their connections through women's organizations than women in the younger cohort, because of the loss of kinship networks members of the older cohort experienced due to the genocide. The role of Rwandan women's organizations in shaping the lives of women within the country remains unclear at this time. Many women's organizations developed fairly recently and women's social agency continues to undergo change, making women's organizations' effectiveness in providing support a relevant area of study. 


\section{Theoretical Framework}

Agency and Desire

Objectives and organization of Rwandan women's organizations should arise from contextual vulnerabilities and needs of women within the area the organization exists. Gender as a subject position strongly impacts the roles individuals occupy in a conflict situation. Subjectivity in this case, refers to individuals in relation to the social structures of power in which they reside. The position of the subject impacts and is impacted by his or her agency. Agency refers to an individual's ability to control and change situations and ultimately the course of their life. Women's level and forms of agency vary dependant on the social structures in which those women are housed. However, through the construction of the sex label "female" roles, appearances and expectations for individuals are constructed and deemed as natural by global society. According to Butler 1997, the construction of sex categories limit bodies to an unattainable "ideal" (532). Many conceptions of the ideal type female physical form and female desires find their base in Western projections of womanhood. However, universal pursuits and desires do not exist within the global category of women, because the global category of women represents vastly dissimilar groups and individuals. Different women with disparate "affinities" desire various pursuits within their lives (Haraway 1999:157).

Prominent social institutions impact the desires and abilities of individual women. The goals of women, and more broadly all humans, are influenced by desire (Hafez 2011:3). Desire "creates and, in turn, is created by cultural and social experiences, by historical traditions, state agendas and by individual negotiations" (Hafez 2011:3-4). Agency and desire form at the intersection of a variety of socially significant identities and memberships. Utilizing the metaphor of the rhizome, Deleuze and Guattari 1987 express how desire and historicity do not 
occur directionally but rather continue to expand through time and space expounding "and...and...and" (25). Deleuze and Guattari 1987 posit existing "between things does not designate a localizable relation going from one thing to the other and back again" (25). Hafez (2011) demonstrates the ability of secular thought and religious sentiments to mutually influence the desires or affinities of women (161-162). Many women do not occupy one space either religious or secular at any given moment, but rather continually operate between the two with no clear distinctive separation.

Global Feminism

Universal feminism, operating on the assumption that a uniform form of gender equality exists transnationally, proves undesirable because differences exist between women internationally. Feminist theory largely represents "third world" women as lacking and juxtaposes their lives to the supposed superior lives of Western women (Escobar 1995:8). The representation of "third world" women as lacking relative to western women privileges and hegemonizes Western ideology, allowing western feminists to exercise power over "third world" women (Escobar 1995:8). Feminist approaches employing “universalism” impose notions of equality "based on the experiences of women who [are] white," and are therefore similar to “male universalism" which feminism intends to oppose (Evans 1995:21). Inequality on the basis of gender remains a global issue that requires attention applied contextually and not privileging a specific conception of womanhood (Chambers 2008:47).

Expanding the definition of feminism to include all those who seek greater autonomy and equality for women through a variety of endeavors allows inclusivity of non-western women, including Rwandan women, in the category. Previous anthropological studies give insight into 
non-western feminism (e.g., Hafez 2011; Burnet 2012). The content and organizational structure of Rwandan women's lives shifted as a result of international attention and influences in the country as well as the recent drastic social change. Danielle de Lame states in A Hill among a Thousand that “... the only social status possible for a woman. [is] that of a wife and mother” (2005:385). However, following the large scale social upheaval of the 1994 genocide, many women were left widowed or otherwise single. Shifting social spaces occupied by women in Rwanda offers an opportunity for understanding the importance of context in subject making and subsequently feminist movements. Women's groups occupy a space that allows for increased political presence, if not increased political agency, of women within Rwanda.

Acknowledging Rwandan women's organizations as feminist establishes their efforts towards gender equality as equally valuable to Western feminist efforts and ideologies. By acknowledging non-western social movements as equally viable the international aid and development community can begin to practice top down and bottom up development strategies in tandem (Autesserre 2010). Ignoring local level trends presents problems because the aid will fail to address significant issues affecting the recipients of aid. Cultural understandings shape the form aid takes (Autesserre 2010:41). International aid organizations and policy makers approach issues of violence from the "top-down;" as a result they generally ignore "local” level or “subnational” factors (Autesserre 2010:43). Grass-roots level organizations, such as Pro-Femme Twese Hamwe, serve to the best interest of responsible social development. Localized development efforts mitigate issues such as ill-equipped universal standards and allow for development of consciousness among the populous. Engle Merry (2006) claims, localized social change presents two primary challenges: presentation in a way to gain local acceptance while challenging existing inequality and negotiating local needs with donor's desires (5). Gaining 
funding remains a challenge. The dependence of Rwandan women's organizations on international donors creates a degree of subservience. Higher prestige value assigned to local movements may mitigate the level of dominance currently held by international donors over Rwandan women's organizations.

\section{Historical Context}

\section{Genocide}

The 1994 genocide's origins lie as far back as the colonial period. Belgian colonists constructed a hierarchy of rigid ethnic categories from previously transient social distinctions through employment of the Hamitic hypothesis. The Hamitic Hypothesis found its origin in Western racist notions about African people in the late 18th century. The Hypothesis was bolstered by Biblical stories which attributed Africa's misfortune to the curse on Ham (Eltringham 2006: 427). The hypothesis asserts that "Hamitic race" as superior to other Africans, as it is considered a sub-group of the Caucasoid race (Eltringham 2006). German and then Belgian colonist brought and applied the Hamitic Hypothesis to Rwandan people in the early 20th century. Their assignment of the three ethnic categories: Hutu, Tutsi and Twa led to large scale social inequality along ethnic lines. Colonists showed preferential treatment to those classified as Tutsi as the supposed "Hamitic race". Reverberations from colonial implanted racism persisted into the late 20th century and present day.

A history of physical and structural violence played a major role in establishing dynamics necessary for genocide to occur in Rwanda (Uvin 1998). Violence in the early 1960s led to large refugee populations in surrounding nations (Newbury et al 2001:27). Large encampments and 
influxes of refugees established the pattern in which refugee groups served to determine ethnic identities and their current significance within the political context of the region (Lemarchand 2009:20). The RPF, largely composed of Tutsi refugees returning to Rwanda, invaded the country in October of 1990 (Lemarchand 2009:73).

The Hutu extremist government in Rwanda at the time created a state of panic and instituted genocide against ethnic Tutsis. The Hamitic hypothesis was reframed in order to discredit the entire Tutsi ethnicity and cast all those identified as Tutsi as RPF collaborators (Lemarchand 2012:63). The construction of a myth allowed the state to justify and encourage ethnic violence between civilians (Lemarchard 2012:68). A significant portion of violence in 1994 was perpetrated against women, including but not limited to Tutsi women. During instances of violence prior to 1994 women and children were generally spared as well as those who sought refuge in churches. However the 1994 genocide was different and Tutsi men, women, and children were slaughtered in large numbers inside church buildings as well as at other locations (Newbury et al. 2001:27).

Starting on April 6 and continuing through July 4, 1994, an estimated 800,000 Rwandans were killed in a state-sponsored genocide (Lemarchand 2009:69). During the violence in 1994 many women, both Tutsi and Hutu, were victims of sexual assault and abuse; additionally women of all groups experienced loss of family, friends, and economic stability (Newbury and Baldwin 2001:28). The former youth wing of the MRND political party (National Republican Movement for Democracy and Development) called the Interahamwe slaughtered Tutsi men, women and children at roadblocks, in their homes, and at public buildings such as schools and churches. Violence engulfed the state of Rwanda until July of 1994 when the genocide ended and the RPF took governing control of Rwanda. 
Acknowledging the constructed and unstable nature of the ethnic identifiers, Tutsi and Hutu, is vital to understanding the genocide and current social climate in Rwanda (Straus 2006:22). An understanding of the instability of ethnic identities and transparency of ethnic identities results in questioning past analyses of the genocide. Superficial analysis claims historic ethnic hatred caused the genocide; however, framing the genocide through a lens of historical ethnic hatred oversimplifies the issue. The genocide did occur across ethnic and gendered lines. Individuals' victimization or participation was influenced by his or her gender and ethnicity. However, the genocide was organized by the government and implemented as a political strategy. Although it is constructed and does not account for the entirety of the genocide, ethnicity influences the lives of Rwandans.

The genocide profoundly impacted the lives of Tutsi women. The current subject positions and subsequent desires of Tutsi women were shaped by events of the genocide. Hate media, including iconography and textual messages, disproportionately targeted Tutsi women (Lemarchand 2009:61-63). Institutions encouraged sexual violence against Tutsi women through depiction of supposed dangers of "Tutsikazi," or Tutsi women (Lemarchand 2009:63). Media sources such as the periodical "Power" used sexually explicit images of Tutsi women in order to "discredit" the entire ethnicity and cast all Tutsis as "[allies] of the RPF and hence [enemies] of the Hutu nation" (Lemarchand 2009:63). The Interahamwe murdered large numbers of Tutsi women "often after having subjected [them] to sexual violence and torture" (Newbury et al 2001:27). Sexual exploitation of Tutsi women did not disappear completely following the RPF takeover. Social pressures forced women into "relations with soldiers as a sign of gratuity" (Newbury et al 2001:31). Tutsi women who survived the genocide were targets during and after 
the conflict for sexual exploitation. Women also experienced hardships such as: separation from kin, loss of land and psychological trauma.

Hutu women experienced the 1994 genocide and changes following its conclusion differently than Tutsi women. The events of 1994 molded social positions and desires of Hutu women. The victimization of Hutu women remains overlooked for two primary reasons: strong association with Hutu ethnicity and perpetration as opposed to victimhood, and cultural stigma associated with reporting instances of rape. Burnet (2009) discusses victims of sexual violence and how victimization occurred in the case of a Hutu woman, Seraphine (90). Seraphine was repeatedly raped by an Armed Forces of Rwanda (FAR) soldier with complaisance for fear of her Tutsi husband, whom she had hidden in her home, be found out if she resisted (Burnet 2009:90). Aside from her status as a Hutu and therefore symbolic association with "perpetrator" and "guilty" Seraphine still faced other hindrances to the receipt of justice for her suffering (Burnet 2009:80). The dynamic of the gacaca courts in Rwanda coupled with stigma assigned to victims of rape nearly always prevent women reporting their rape (Waldorf 2006:62-63). The current court system and government dynamic do not provide justice and reparations necessary

for the country to reconcile. The gacaca courts have failed because they misapply an early conflict resolution system never intended for large scale and extreme conflicts such as genocide, murder, or rape.

\section{Ethnicity and Gender in Post-Genocide Rwanda}

Following the conclusion of the 1994 genocide, the RPF seized control of the country and outlawed the recognition or discussion of ethnic categories. However, ethnic identities continued to impact women's lives. The formal abolition of ethnicity by the current Rwandan government allows for the maintenance of an "ethnic dichotomy (Hutu-Tutsi) by politicizing victimhood" 
(Burnet 2009:80). The subject positions of Tutsi and Hutu women in post-genocide Rwanda differ because the genocide occurred across ethnic boundaries. Women from all groups experienced large scale loss; however the form of loss depended heavily on ethnic identities. To understand the "subject making" of Rwandan women in 2014, international aid agencies must understand experiences of women during the1994 genocide.

Tutsi men and women continue to suffer because of their ethnicity. Preserved corpses and remains of genocide victims, predominantly Tutsi, remain on display in genocide memorials as part of a government endeavor to ensure remembrance. (Burnet 2012:101). The current government has also held a variety of national level memorials that often culminate in mass graves (Burnet 2012:101). Exploitation of bodies after death leads to suffering for the living. Continued disrespect on the part of government programs and initiatives increases pain and suffering of those Tutsi who survived the genocide as they see kin and other individuals denied appropriate burials and religious rites (Burnet 2012:101). The government possesses political motives in addition to remembrance for exploiting the bodies of the dead. The Rwandan and international public remain cognizant of perceived divisions between Hutu and Tutsi individuals as either victims or perpetrators through government propaganda in the form of mass grave ceremonies. Perpetuating divisions within the population ensures continued control of the government by the RPF. Rwandans may elect to remove the current government in favor of true democracy or some other form of government organization if given the opportunity to collectivize.

Following RPF invasion the situation for Hutu women was precarious. Hutu women were “beaten, raped or otherwise humiliated by RPF soldiers" in various instances (Newbury et al 2001:31). Hutu women experience social, economic, health, and other strains resultant from the 
genocide. Hutu widows and women separated from their husbands for a variety of other reasons experience resource insecurity (Burnet 2012:116-117). Other Hutu women, whose husbands remained listless and unemployed as a result of Post Traumatic Stress Disorder (PTSD), support their household as the primary earner while also performing domestic gendered labor (Kumar 2001:10). Women who do not have a spouse are subject to social stigma and emotional trauma. Those women whose husbands no longer work must compensate by performing all labor necessary to run a household and care for their husband.

The common representation of the genocide by the RPF government "transfer[s] guilt and blame to all Hutus and the international community," thus leading to social isolation and forced silence in mourning of Hutu genocide victims (Burnet 2012:112). Clear boundaries of victim and perpetrator along the lines of Hutu and Tutsi do not exist (Burnet 2012). However various social and cultural scripts and performances reify the victim-perpetrator dichotomy. For instance, during national mourning ceremonies individuals often accuse others of participating in the genocide (Burnet 2012:101). Ethnicity and overt racism remain illegal in Rwanda; however, the replacement of ethnic terms with the morally loaded labels victim and perpetrator institutionalizes racist sentiments and actions. The government utilizes the perpetrator-victim dichotomy to maintain dominance and control over the majority of the Rwandan population, Hutus.

\section{Insecurity for Women in Post-Genocide Rwanda}

Violence in Rwanda did not end in the summer of 1994. The events of 1994 impacted women from of all ethnicities, social classes, and regions of Rwanda. Excluding impacts on women who participated in genocide; women face two primary long term impacts: social stigma 
as a result of rape and "women headed" households (Newbury et al 2001:30-32). Both led to stress, anxiety, and decreased quality of life for women and also those dependent on them, often their children. Physical and emotional insecurities among women are a result of maltreatment during and following the events of 1994. Historically in many instances of violence, particularly genocide or civil war, assaults and maltreatment of women continue after the conclusion of recognized conflict.

Two primary forms of violence effect women in Rwanda today: physical violence and structural violence. Preexisting structural violence against women disposes them to harsher treatment in periods of high physical violence. Structural violence such as gender inequality “increases potential” for “acute violence,” or instances of physical violence (Uvin 1998:107). The cultural subjugation of the woman makes her more susceptible to gross human rights violations during times of turmoil, such as following an armed conflict situation. The international community undermines large scale victimization of women by applying the label “official" to organized violence of a certain scale (Handrahan 2004:430). Labeling violence as officially concluded trivializes subsequent experiences of women in areas that have undergone serious upheaval. Continued suffering of women at the hands of former combatants does not fall under the international community's definition of official violence. Official violence gains recognition from the international community because of its large scale, "micro-level dynamics" provide a "foundation for the national and regional fighting" (Autesserre 2010:142). National level tension and local level violence share a cyclical relationship, wherein the existence of one perpetuates the other. By labeling a country as "post-conflict" the international community recognizes it as a place of relative non-violence. The "post-conflict" status of a country alludes 
to relative safety for inhabitants; however the label does not represent reality for a significant number of Rwandan women.

Women living in Rwanda fall victim more frequently to: domestic violence, gang rape, coercion into prostitution and trafficking in part due to high national-level tension (Handrahan 2004:434). As discussed previously in the segment on Hutu women in post genocide Rwanda, shame limits women from reporting rape and sexual abuse (Handrahan 2003:434). Women rarely receive care for injuries obtained as a result of rape nor do they receive justice for the crime. Victims of rape commonly face coercion, illness and stigma lessening the overall quality of their lives (Newbury et al 2001:31). Social stigma from rape strongly impacts the outcomes of women's lives. Women were commonly pressured into prostitution because "they were already social outcasts because of their experiences" (Newbury et al 2001:31). Women in conflict and post-conflict situations are commonly exploited and abused sexually. Abuse of Rwandan women persists because the international community remains blind. The international community's definition of conflict does not represent reality.

In addition to physical assault and exploitation scores of women also experience economic and resource insecurity. Widows have difficulty operating in Rwandan society as a result of "second class status and a variety of legal constraints in both customary law and written legal code" (Newbury et al. 2001:36). Widows generally have a difficult time accruing resources necessary for themselves and their children. The assignment of widows to second class legal and social status as well as difficulty obtaining goods necessary for survival experienced by widows place social and economic pressure on women. The importance of women's organizations and networks increases due to high pressure experienced on the part of individual women lacking strong kinship ties. Women lacking social ties apart from organizations consisting of their peers 
are likely to become highly dependent on those organizations for physical, emotional, and perhaps financial support in times of duress.

Rwandan Women's Organizations

As the country started to rebuild, women's Civil Society Organizations (CSOs) played important roles in reconstruction. Women's organizations replaced missing kin groups and “social support systems” destroyed in the genocide (Burnet 2008:366). The Rwandan women's movement existed prior to 1994, however, as a result of the genocide structure and direction of the movement shifted (Burnet 2008:366). Women continue to gain increasing representation in political office as a result of international pressure for gender equality. However, while women increasingly hold more offices in Rwanda, the dynamics of the current government do not warrant them significant influence within those offices. As the agency of women within the government remains limited, women's agency through other avenues, such as CSOs, warrants attention. Recent shifts in development focus continues to draw global attention to the position of women's organizations within society (Escobar 1995:154-211). International development agencies' focus on women established a discourse between western feminists and Rwandan women. Increased attention to global women's rights necessitates contextual analysis of women's lives. Understanding the desires and goals of women within their social, historical, racial, religious, cultural and economic context will create for more astute movements for gender equality as well as equality across other social identities such as nationality (Hafez 2011).

Women's organizations in many countries including Rwanda developed under western influence because of the recent fetishization of gender issues. Many resources necessary to operate Rwandan women's organizations come from international aid. Women now occupy a 
“central space as subjects, objects, and conceptualizers of development" (Escobar 2012: x). Aid and development create a power dynamic in which Western feminists may exercise power over nonwestern women by acting as "conceptualizers of development" (Escobar 2012: x). Rwandan women's organizations largely grew out of necessity for social and material support on part of female Hutu and Tutsi genocide survivors. Allowing Rwandan women to conceptualize their own development would counteract some of the negative influences of the discourse between western and non western feminists. Strain resulted in a need commonly filled by forming women's organizations and groups. National tension impacted the lives of women from diverse social and political statuses. Commonality of women in "desperate circumstances" mainly from "economic hardship" and "social isolation" resulted from large scale death, imprisonment, and separation from previous social networks, including kin networks (Newbury et al 2001:98). A woman's access to land in Rwanda is "guaranteed" and "protected" through male kin; widows commonly lose land access without a male kin connection (Burnet 2012:140). The issue of land scarcity has plagued Rwanda even prior to the events of 1994; the disenfranchisement of individuals from land would have led to desperation and anxiety. Various women's organizations exist for the purpose of aiding women who have lost kin as a result of the violence that occurred in 1994. One such organization is called Association des veuves du genocide de l'avril 1994, April 1994 Genocide Widows Association (AVEGA). AVEGA is a sub-organization of ProFemme Twese Hamwe and expresses the primary goal of aiding genocide widows. AVEGA provides a variety of services including education on rights to land and how to become self sustainable through the organization of women's cooperatives. In addition to AVEGA other Rwandan women's organizations supplement social networks missing large portions of kinship connections. However, women's organizations fail to provide for the interests of all women. 
Women's organizations fail to fulfill the international purpose of elevating the lives of all women because they are not accessible to all women. There are two main types of women's organizations present in Rwanda today: one that "provides assistance to women of one or more particular category" and a second that focuses around a profession or activity which all members are part of (Newbury et al 2001:101). Women's groups within Rwanda do not provide for the interests of all underprivileged groups and are stratified by power relations much like the broader society in which they are located. Rather, women's organizations serve the desires and purposes of the "elite" class of women who maintain membership (Newbury et al 2001:102). Those women who experience the highest levels of need, such as female youth, are largely incapable of accessing resources provided by women's organizations because they lack the capital necessary for membership (Sommers 2012:81). Many cooperatives and other aid organizations require payment for membership. Impoverished and young women often cannot pay these fees, barring them from access. While women's organizations currently fall short in the international effort of aiding all women, they provide resources for the success of many women.

Women's organizations perform a variety of social functions. One of the largest women's organizations currently active is Pro-Femme Twese Hamwe. Pro-Femme Twese Hamwe is an umbrella organization that oversees more than 68 sub-organizations at this time and continues to grow. The directors of Pro Femme Twese Hamwe were integral to recruiting participants for interviews as well as locating translators. Pro Femme Twese Hamwe lists its four primary goals as: to "encourage a culture of peace, combat gender discrimination, promote socioeconomic reconstruction, [and] reinforce the institutional capacity of Pro Femme Twese Hamwe and its member associations" (Newbury et al 2001:104). To execute these goals Pro Femme Twese Hamwe calls on women to participate in political and peace building portions of society 
(Newbury et al 2001:105). By enabling and encouraging involvement in public and political arenas, women's organizations construct new spaces for women within Rwandan society. Burnet (2011) concludes female agency has increased due to these new political spaces, follow up research should assess how long this trend continues and in what directions.

\section{Social Network Analysis}

Social network analysis continues to grow as a field of interest for research. Social network analysis refers to the study of relationship connections between individuals or groups (Scott 2000). Actor-Network Theory (ANT) can add great depth to social network analysis. ANT suggests webs of relation continually generate all things in existence both socially and naturally (Mulcahy and Perillo 2010:128). Utilizing social network analysis tools, approaches and programs can prove useful to social sciences, because it can quantify otherwise unquantifiable questions of study. Social network analysis introduces an objective element that coupled with subjective answers from participants allows for comprehensive understandings of social issues, such as the status of women in Rwanda. The field continues to grow at a slow pace largely because of mathematical components and language necessary (Scott 2000:1).

When constructing an egocentric social network the participant or subject of the network is referred to as "ego" while those individuals who compose ego's network are referred to as "alters". The following image (Figure 2) is an example pulled from this study. Each shape represents ego or alters. The triangles indicate male individuals while the circles indicate female individuals. The color green was used to show alters who are not members of a women's organization. The color pink was used to show individuals who are members of women's organizations. The size of the shape indicates degree centrality. Degree centrality refers to the number of points in a network a particular point is connected to (Scott 2000:83). In other words, 
the number of alters to which one specific alter is connected. Degree centrality is a measure of the level of connectedness of an individual. Shapes that are larger in the image have a higher degree of centrality than smaller shapes. By default, ego possesses the highest degree centrality because this is an egocentric network built around knowledge of a specific number of most significant ties to Ego. The level of support offered by alters to both Ego and other alters is important for this particular network analysis. The image below shows strongest ties i.e., the most support (a four on the likert scale), as black and thick lines and ties ranking the second strongest (a three on the likert scale) as blue and thin lines.

\section{Figure 2}

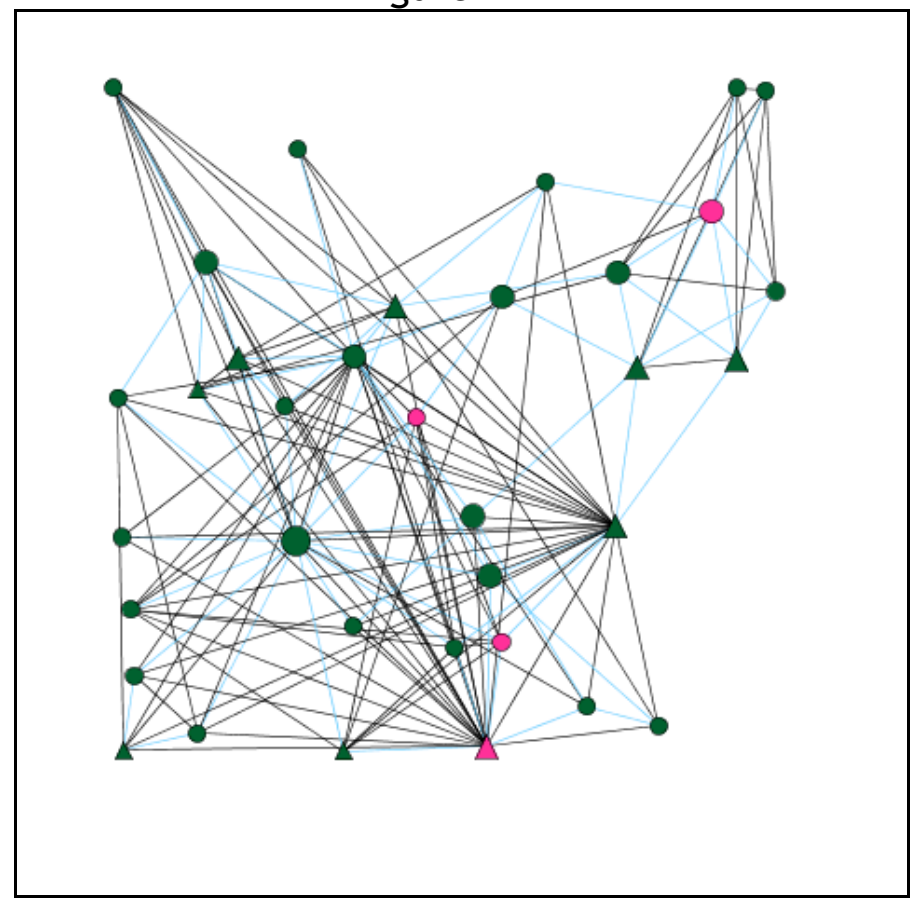

Two primary forms of data relevant to social network analysis exist: attribute and relational data (Scott 2000:2). Attribute data refers to data regarding characteristics of individuals, for instance the gender of a participant or alters they list (Scott 2000:2). Relational data refers to "...contacts, ties, and connections" and cannot be expressed as "properties of 
individual agents themselves" (Scott 2000:3). Relational data within this study is the level of support offered by each alter within a network to all other alters and Ego.

In order to ascertain the level of support shared between points within a network I utilized a method of scoring referred to as Likert scaling. The Likert scales constitute measurements that are “...composed of approximately an equal number of favorable and unfavorable statements concerning the attitude object, is given to a group of subjects" (McIver and Carmines 1981:22). Likert scales allow researchers to measure the degree to which a respondent expresses certain sentiments. Linear measurements of this form should only aim to answer one "single common factor," various sentiments should not be assigned to the same Likert scale question (McIver et al. 1981:23).

Another important concept for measuring the degree to which women rely on various network connections is the concept of cliques, or "sub-set(s) of points in which every possible pair of points directly connects by a line and the clique is not contained by any other clique" (Scott 2000:114). Components are similar to cliques; however, the connections are not necessarily direct (Scott 2000:101). All points in a component are connected through "one or more paths, but they have no connections" outside of that component (Scott 2000:101). Figure three depicts both cliques and components. A large component of predominately green nodes, non-members of women's organizations, appears at the bottom right hand corner of the image. A clique of four alters who do maintain membership in a women's organization appears at the bottom left hand corner. The one alter on the bottom is not a member of the clique because she only shares a tie with one member, not all members. 
Figure 3

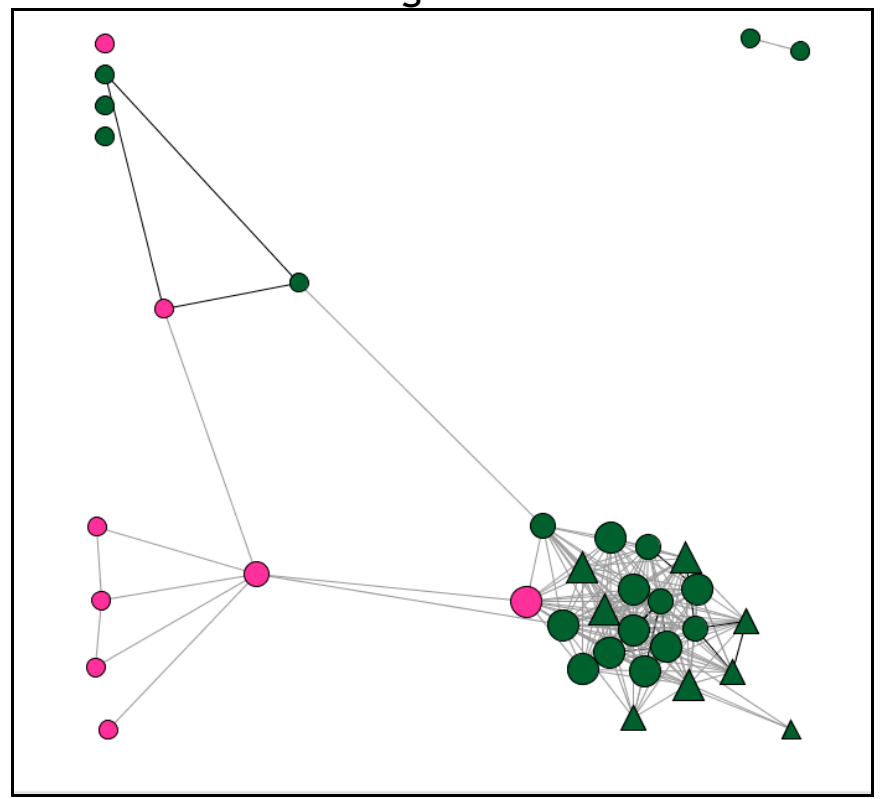

\section{Research Methods}

Participants

Participants were recruited for a study examining levels of support and dependency of Rwandan women on their respective women's organizations. The study area was Kigali, Rwanda during a four week period between May 2013 and July 2013. Women were eligible for the study if they were age eighteen or older, were a member of a women's organization and fell into either the older cohort (born in 1969 or earlier) or younger cohort (born in 1970 or after). Pro-Femme Twese Hamwe and our translators helped to recruit eligible participations by inviting them to learn more about the study and decide whether or not to participate. Participants were members or beneficiaries of one of Pro-Femme Twese Hamwe's member organizations including, AVEGA, Methodist Mother's Group, Rwandan Girl Guide's Association (AGR), CNF, Femmes en Dialogue, Dukundane (“Let's Love Each Other”), Association des Enfants et Jeunes Travailleurs (AEJT), Kanyarwanda, Rwandan Association of University Women, Duterimbere 
(Association of Domestic Workers), Hagaruka, women's farming co-operatives, Abategarugori Maranatha (Women of Maranatha). Women came from a broad array of positions within their organizations as well as broad array of organization types. Participants ranged from highly involved leaders to beneficiaries of organizations. Organizations ranged from those which provide legal aid, to those that provide for economic well being, psychological support, and social support.

\begin{tabular}{|l|l|l|l|}
\hline \multicolumn{4}{|c|}{ Table 1 - General Subject Information } \\
\hline & Total Sample & Older Cohort & Younger Cohort \\
\hline $\begin{array}{l}\text { Year Joined Women's } \\
\text { CSO as an Adult }\end{array}$ & $1970-2011$ & Before 1994 & After 1994 \\
\hline Birth Year & $1952-1993$ & 1969 or Before & 1970 or After \\
\hline Average Age & 39 years old & 49 years old & 28 years old \\
\hline Interviewees & 29 & 15 & 14 \\
\hline
\end{tabular}

Thirty women in total were interviewed; 15 belonging to either age cohort, however due to technical issues one interview was irretrievable. Twenty nine interviews were used for data analysis, 15 of which belong to the older cohort and 14 of which belong to the younger cohort. On average, the twenty nine women who participated in the study were 38 years old. A small majority $18(58 \%)$ were natives of Kigali. The majority of the women (97\%) reported high levels of support within their women's organization.

There are a few notable limitations to the sample of participants, the primary being the high level of unemployment. Because it was necessary to conduct interviews during normal business hours, the majority of participants were unemployed. An additional bias of the data comes from the intentional selection of women who were members of women's CSOs. Selecting 
women under the prerequisite of membership in a women's organization makes comparison between women who participate in women's CSOs and women who do not impossible.

Procedure

Individual computer-assisted face-to-face structured interviews were conducted by one researcher and one translator. Women were paid 6,000 RWF or approximately $\$ 12$ for their participation. Interviews averaged between two and a half and three hours in length. Interviews were conducted in English when possible but more often in Kinyarwanda (the local language) or French. Translators aided in entering the names of alters into EgoNet, other information was entered by either myself or Joanna Thompson, another University of Louisville anthropology major who collaborated in data collection. Participants were not directly asked questions regarding their ethnicity because recognizing ethnic categories remains illegal in Rwanda. All participants were provided the appropriate consent information before the start of each interview. Participants were provided with informed consent documents before the start of every interview and understanding and consent were gained verbally. Participants did not sign informed consent documents as they would be the only potential breech to maintaining their confidentiality. Maintaining confidentiality of participants was of the utmost importance due to current social and political climates in Rwanda.

The research protocol was approved by the Institutional Review Board at the University of Louisville. Funding for this project was obtained through the National Science Foundation to support Michelle Fox's travel and research expenses and the Irvin F. and Alice S. Etscorn Charitable Foundation International Summer Research Award to support Joanna Thompson's travel and research expenses. 


\section{Study Variables}

\section{Background Characteristics}

We collected demographic information on participant's age, gender, educational level, whether or not they were a native of Kigali, women's organization membership status and 35 closest alters as well as the level of support shared between each alter and the participant. We collected demographic information on the 35 alters' age, gender, educational level, women's organization membership status and the level of support shared between each alter listed.

\begin{tabular}{|r|l|}
\hline \multicolumn{2}{|c|}{ Table 2 - Structured Interview Guide } \\
\hline General Information & $\begin{array}{l}\text { Age, Gender, Age at start of involvement, Organization involved in, } \\
\text { positions held within organization, occupation }\end{array}$ \\
\hline Network Information & 35 alters \\
\hline Alter Information & $\begin{array}{r}\text { Age, Gender, Relation, Occupation, Membership in women's } \\
\text { organizations, Positions held within organization, }\end{array}$ \\
\hline Quentions & $\begin{array}{l}\text { 1. Are you a native of Kigali, if not why did you relocate here? } \\
\text { 2. Do you feel you rely more or less heavily on your connections } \\
\text { through women's organizations than those apart from the } \\
\text { organizations? }\end{array}$ \\
& $\begin{array}{l}\text { 3. How did you come to be involved in your organization? } \\
\text { 4. How has your involvement in women's organizations } \\
\text { benefited you? }\end{array}$ \\
5. What are some of your long term goals? \\
\hline
\end{tabular}

Network Elicitation

EgoNet is a data analysis program developed by Dr. Christopher McCarty to facilitate collection and analysis of egocentric network data. The interview for this project included questions about ego's gender, age, membership in women's organization, educational attainment, occupation and religious affiliation. After responding to these questions about themselves participants were asked to list the names of 35 people they "knew," defined as "knowing means 
you know them and they know you by sight or by name. You have had some contact with them in the past two years, either in person, by phone, by text message, email, or Facebook, or by mail, and you could contact them again if you had to. They can live anywhere in the world." Participants were asked to begin with the people who were "most important" to them. Participants were instructed to list alters by distinct names so that they could answer follow up questions about them later. All interviewers and translators used the same prompts and probes while conducting interviews to ensure uniform data collection.

\section{Network Composition and Relationship Characteristics}

The composition of each woman's personal network was assessed by asking a series of questions about each alter. We asked about alters' gender, age, educational attainment, occupation, women's organization membership status and religious affiliation.

Participants were also questioned about their relationship with each alter. Relationships were assessed on the basis of support provided between the participant and each alter. Additionally, participants were asked to provide information regarding the level of support between each alter within their network and all the other alters in their network. Support was defined as including "financial, emotional, and social support and things such as friendship, social visits, sharing a meal, contributions for weddings or funerals etc." that was provided within the last 12 months. Support was measured using a Likert scale from one to four $(1=N o$ Support, 2=A Little Support, 3 = A Fair Amount of Support and $4=$ A Lot of Support). The final portion of the EgoNet interview component of the study matched each alter in the order in which they were listed with all other alters listed in the network and asked about the degree of support offered between the two using the same Likert scale. 
A qualitative interview was administered after the completion of each EgoNet-based interview. The qualitative interviews focused on gaining more opinion based answers from subjects on how they viewed their own subject position within Rwanda and what benefits they received from their involvement with their respective women's organizations. Questions were included about women's involvement in women's civil society organizations (CSOs), including when and how they joined, their reasons for joining, and their motivations in remaining active in the organizations.

\section{Results}

Data gathered from the EgoNet portion of the interviews was analyzed through the use of EgoNet software and image creation. Interview results including: degree of centrality, gender of alters, religion of ego, religion of alters and women's organization membership of alters were viewed separately for Elder Cohort and Younger Cohort as well as comprehensively for the entire sample. Compositional summary statistics were generated from each interview by the EgoNet interview software. I created Microsoft Excel spreadsheets for these summary statistics

for both cohorts and then noted the mean and mode for each. This information was then used to answer my research question: Are women within the elder cohort more dependent on their networking ties through women's organizations due to depletion of male kin as a result of the genocide?

\section{Network Composition}

Each participant named 35 members of her personal network, resulting in a total of 1,015 named alters. The older cohort accounted for 525 of these alters, while the younger cohort accounted for the remaining 490. Members of women's organizations comprised 350 (35\%) of 
the 1,015 alters. Members of women's organizations comprised $187(36 \%)$ of the 525 alters in the older cohort. Members of women's organizations comprised $162(33 \%)$ of the 490 alters in the younger cohort. Female alters accounted for $700(69 \%)$ of the total 1,015 alters. Female alters accounted for 368 (70\%) percent of the 525 alters in the older cohort. Female alters accounted for $333(68 \%)$ of the 490 alters in the younger cohort. Conversely, male alters accounted for $315(31 \%)$ of the total 1,015 alters. Male alters accounted for $158(30 \%)$ of the 525 alters in the older cohort. Male alters account for $157(32 \%)$ of the 490 alters in the younger cohort.

Thirteen participants in the older cohort (87\%) have networks composed of a majority of female alters, while only 2 participants (13\%) within older cohort had more male alters within their networks (see Table 3 below). Thirteen participants in the younger cohort (93\%) have networks composed of a majority of female alters, while only one participant (7\%) within younger cohort had more male alters than female alters within her network. What is not apparent by simply looking at the table is the degree to which majority was obtained by either gender. Between all interview subjects male majority was never more than 20 alters (57\%) of a network with a mode of 18 alters (51\%) for majority male networks. Female majority was as high as 31 alters $(88 \%)$ with a mode of 25 alters $(71 \%)$.

\begin{tabular}{|l|l|l|l|}
\hline \multicolumn{3}{|c|}{ Table-3 Gender of Alters } \\
\hline & Total Sample N (\%) & Older Cohort N (\%) & Younger Cohort N (\%) \\
\hline Male & $315(31 \%)$ & $158(30 \%)$ & $157(32 \%)$ \\
\hline Female & $700(69 \%)$ & $368(70 \%)$ & $333(68 \%)$ \\
\hline
\end{tabular}


Alters' Involvement in Women's Organizations

The entire sample includes 350 (35\%) alters who are members of women's organizations.

The older cohort accounting for 187 (37\%) and the younger for $162(33 \%)$ alters who are members of women's organizations. Alters who maintain membership in a women's organization represent a high level of support according to qualitative interview statements by participants. Twenty-two (76\%) participants stated during the qualitative interview they relied the most heavily on their connections through women's organizations. Specific reasons for support such as resources or emotional support were discussed depending on the organization the participant maintained membership in. The remaining seven (24\%) participants stated support provided through women's organizations was secondary or even tertiary to support through other social institutions, most notably their kin. Thirteen (87\%) of the 15 older cohort participants stated they relied the most heavily on the support provided through their respective women's organization. Nine $(64 \%)$ of the 14 younger cohort participants stated they relied the most heavily on the support provided through their respective women's organization.

Table-4 Rely More Heavily on Connections Within Women's Organization than Apart From

\begin{tabular}{|l|r|r|r|}
\hline & Total Sample N (\%) & Older Cohort N (\%) & Younger Cohort N (\%) \\
\hline $\begin{array}{l}\text { Participants who rely more } \\
\text { heavily on Women's } \\
\text { Organization Connections }\end{array}$ & $22(76 \%)$ & $13(87 \%)$ & $9(64 \%)$ \\
\hline
\end{tabular}

Table-5 Alters Who are Members of Women's Organizations 
Nine participants (31\%) of the entire sample exhibit social networks wherein the majority of alters were also members of women's organizations. Among these nine participants the mode of alters who were members of women's organizations is $21(60 \%)$ out of the 35 alters in their networks. Among these nine participants the mean of alters who were members of women's organizations is $18(51 \%)$.

\begin{tabular}{|l|r|r|r|}
\hline \multicolumn{3}{|c|}{ Table-6 Participants with Alters Who are (not) members of women's organizations } \\
\hline & Total Sample N (\%) & Older Cohort N (\%) & Younger Cohort N (\%) \\
\hline $\begin{array}{l}\text { Participants who's } \\
\text { networks are comprised of } \\
\text { a majority of alters who } \\
\text { maintain membership in a } \\
\text { women's organization }\end{array}$ & $9(31 \%)$ & $6(40 \%)$ & $3(21 \%)$ \\
\hline $\begin{array}{l}\text { Participants who's } \\
\text { networks are comprised of } \\
\text { a majority of alters who } \\
\text { did not maintain } \\
\text { membership in a women's } \\
\text { organization }\end{array}$ & $20(69 \%)$ & $9(60 \%)$ & $11(79 \%)$ \\
\hline
\end{tabular}

Twenty participants (69\%) of the entire sample had social networks wherein the majority of alters was not members of women's organizations. Of these twenty participants the mode of alters who were not members of women's organizations is 27 (77\%) out of the 35 alters in their networks. Of these twenty participants the mean of alters who were not members of women's organizations is $26(74 \%)$. Six participants $(40 \%)$ of the older cohort exhibited social networks wherein the majority of alters were also members of women's organizations. Among these six participants the mode of alters who were members of women's organizations is $21(60 \%)$ out of the 35 alters in their network. Among these six participants the mean of alters who were 
members of women's organizations is $20(57 \%)$. Nine participants $(60 \%)$ of older cohort had social networks wherein the majority of alters were not members of a women's organization. Of these nine participants the mode of alters who were not members of women's organizations was $27(77 \%)$ out of the 35 alters in their network. Of these nine participants the mean of alters who were not members of women's organizations was 31 (89\%). Three participants $(21 \%)$ of younger cohort had social networks wherein the majority of alters were also members of women's organizations. There was no mode for these interview subjects because only three interviews filled this criteria and all had different percentages of alters who were members of women's organizations. Of these three participants the mean of alters who were members of women's organizations was $21(60 \%)$. Eleven $(79 \%)$ of the women in younger cohort had social networks wherein the majority of alters were not members of women's organizations. Of these women the mode of alters who were not members of women's organizations was $25(71 \%)$. Of these women the mean of alters who were not members of women's organizations was $26(74 \%)$.

Support Levels with Alters As described above, support provided by alters was measured on a Likert scale from one to four. The number four represents the highest level of support and one denotes no support. Participants expressed that 432 (43\%) of the 1,015 alters provided the highest amount of support. The older cohort stated that 231 (44\%) of the 525 alters within their sub-sample provided the highest amount of support. While the younger cohort expressed 201 (41\%) of the 490 alters within their sub-sample provided the highest amount of support. A positive relationship exists with the amount of support provided and the number of alters for that category. This relationship is clearly represented in Table 5 below. 


\begin{tabular}{|r|l|l|l|}
\hline \multicolumn{4}{|c|}{ Table-7 Levels of Support Alters Provide Ego } \\
\hline Support Levels & Total Sample & Older Cohort & Younger Cohort \\
\hline No Support (1) & $78(8 \%)$ & $58(11 \%)$ & $20(4 \%)$ \\
\hline A little Support (2) & $182(18 \%)$ & $79(15 \%)$ & $103(21 \%)$ \\
\hline A fair amount of support (3) & $325(32 \%)$ & $158(30 \%)$ & $167(34 \%)$ \\
\hline A lot of support (4) & $432(43 \%)$ & $231(44 \%)$ & $201(41 \%)$ \\
\hline
\end{tabular}

Religious Affiliations of Alters and Participants

Interview subjects were asked to report both their religion and the religious affiliations of alters' listed. Within the entire sample $26(90 \%)$ participants reported practicing the same religion as the highest portion of alters in their network. While $3(10 \%)$ participants out of the entire sample, reported a different most frequent religion for their alters than their religious affiliation. Within older cohort 14 (93\%) participants reported practicing the same religion as the highest number of alters within their network. Within the older cohort one (7\%) participant reported a different most frequent religion for her alters than her own religious affiliation. She practiced Roman Catholicism along with 13 (37\%) alters. The largest proportion of her alters 14 (40\%) practiced Protestantism. Within the younger cohort $12(86 \%)$ participants reported practicing the same religion as the highest portion of their alters. Within the younger cohort two (7\%) participants reported a different most frequent religion for their alters than their own religious affiliations. The first participant practiced Protestantism along with $5(14 \%)$ alters and the highest proportion of her alters 19 (54\%) practiced Roman Catholicism. The second participant practiced Islam along with $5(14 \%)$ alters and the highest proportion of her alters 21 (60\%) practiced Roman Catholicism. 


\begin{tabular}{|r|l|l|l|}
\hline \multicolumn{4}{|c|}{ Table-8 Religions of Participants } \\
\hline & $\begin{array}{l}\text { Total Sample } \\
\text { N (\%) }\end{array}$ & $\begin{array}{l}\text { Older Cohort } \\
\text { N (\%) }\end{array}$ & $\begin{array}{l}\text { Younger Cohort } \\
\mathbf{N}(\%)\end{array}$ \\
\hline Roman Catholic & $13(45 \%)$ & $7(47 \%)$ & $6(43 \%)$ \\
\hline Protestant & $3(10 \%)$ & $1(7 \%)$ & $2(14 \%)$ \\
\hline Anglican & $0(0 \%)$ & $0(0 \%)$ & $0(0 \%)$ \\
\hline Presbyterian & $0(0 \%)$ & $0(0 \%)$ & $0(0 \%)$ \\
\hline Born Again Christian & $6(21 \%)$ & $2(13 \%)$ & $4(29 \%)$ \\
\hline Pentecostal & $0(0 \%)$ & $0(0 \%)$ & $0(0 \%)$ \\
\hline Seventh Day Adventist & $1(4 \%)$ & $0(0 \%)$ & $1(7 \%)$ \\
\hline Jehovah's Witness & $0(0 \%)$ & $0(0 \%)$ & $0(0 \%)$ \\
\hline Muslim & $3(10 \%)$ & $2(13 \%)$ & $1(7 \%)$ \\
\hline Agnostic & $0(0 \%)$ & $0(0 \%)$ & $0(0 \%)$ \\
\hline Other & $3(10 \%)$ & $3(20 \%)$ & $0(0 \%)$ \\
\hline I am not sure & $0(0 \%)$ & $0(0 \%)$ & $0(0 \%)$ \\
\hline & & & \\
\hline
\end{tabular}

\begin{tabular}{|l|l|l|l|}
\hline & \multicolumn{3}{|c|}{ Table- 9 Ego and Proportion of Alters Sharing a Religion } \\
\hline & Total N (\%) & Older Cohort N (\%) & Younger Cohort N (\%) \\
\hline Highest & $\mathbf{2 6}(\mathbf{9 0} \%)$ & $14(93 \%)$ & $12(85 \%)$ \\
\hline Other & $\mathbf{3 ( 1 0 \% )}$ & $1(7 \%)$ & $2(15 \%)$ \\
\hline
\end{tabular}

Roman Catholicism represented the most frequent religious classification of alters within 14 (48\%) of the 29 networks. Within the older cohort six (40\%) participants expressed networks where Roman Catholicism was the most frequent religion practiced by alters. While within the younger cohort eight (57\%) participants expressed networks where Roman Catholicism was the most frequent religion. Other common classifications shared by participants and the largest portion of their alters include: Born Again Christian, Protestant, Muslim and other. 


\begin{tabular}{|r|l|l|l|}
\hline \multicolumn{4}{|c|}{ Table-10 Religions of Alters } \\
\hline Religion & $\begin{array}{l}\text { Total Sample } \\
\text { N (\%) }\end{array}$ & $\begin{array}{l}\text { Older Cohort } \\
\text { N (\%) }\end{array}$ & $\begin{array}{l}\text { Younger Cohort } \\
\text { N (\%) }\end{array}$ \\
\hline Roman Catholic & $451(44 \%)$ & $221(42 \%)$ & $230(47 \%)$ \\
\hline Protestant & $112(11 \%)$ & $53(10 \%)$ & $59(12 \%)$ \\
\hline Anglican & $5(0.6 \%)$ & $0(0 \%)$ & $5(1 \%)$ \\
\hline Presbyterian & $2(0.1 \%)$ & $0(0 \%)$ & $2(0.3 \%)$ \\
\hline Born Again Christian & $187(18 \%)$ & $74(14 \%)$ & $113(23 \%)$ \\
\hline Pentecostal & $20(2 \%)$ & $10(2 \%)$ & $10(2 \%)$ \\
\hline Seventh Day Adventist & $61(6 \%)$ & $31(6 \%)$ & $30(6 \%)$ \\
\hline Jehovah 's Witness & $4(0.3 \%)$ & $2(0.3 \%)$ & $2(0.3 \%)$ \\
\hline Muslim & $51(5 \%)$ & $41(8 \%)$ & $10(2 \%)$ \\
\hline Agnostic & $10(1 \%)$ & $5(1 \%)$ & $5(1 \%)$ \\
\hline Other & $74(7 \%)$ & $74(14 \%)$ & $0(0 \%)$ \\
\hline I am not sure & $31(3 \%)$ & $16(3 \%)$ & $15(3 \%)$ \\
\hline & & & \\
\hline
\end{tabular}

A clear pattern existed among all interviews with regards to religious affiliation. There were three major ways in which the religion of alters appears in networks. The first is where the religious affiliation forms its own separate and strong component. The first image below represents this network formation. The orange symbols represent Islamic individuals, which is the religion of the participant whose network this displays. The dark blue represent Roman Catholic individuals, the light blue represent Protestant individuals and the pink represents uncertainty of the individual's religion. Support, gender and degree centrality are represented in the same way as in the example image earlier in the paper. 


\section{Figure 4}

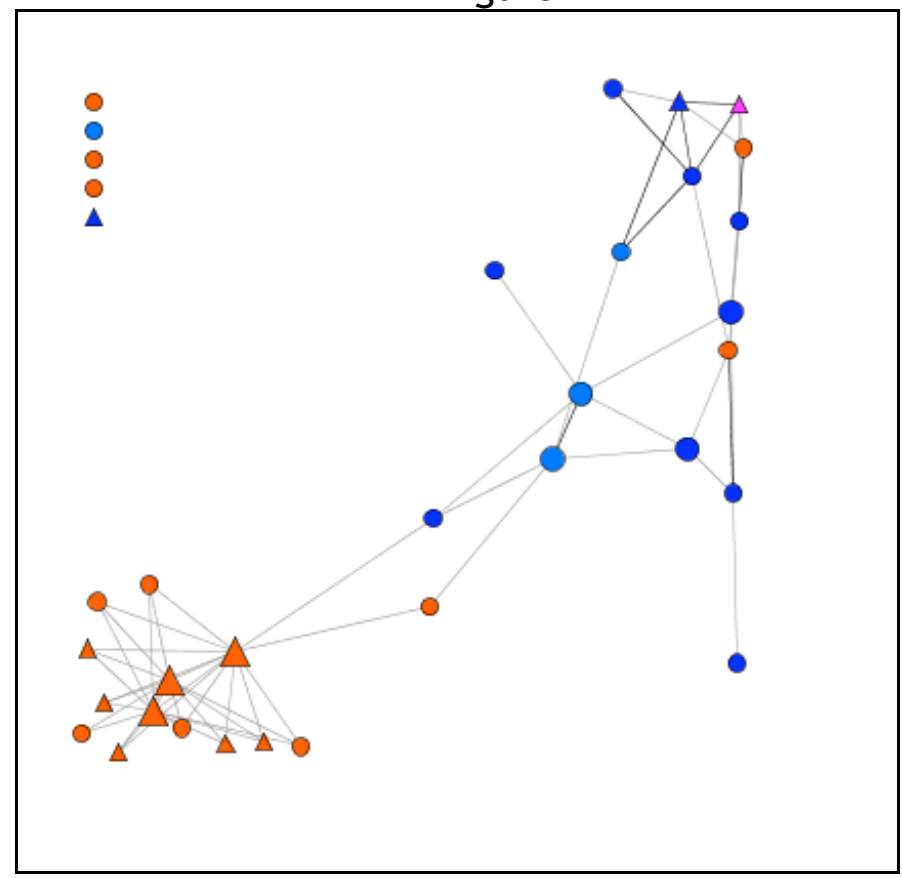

The second pattern of alters' religious affiliation includes numerous cliques of members of the same religion as the participant. Figure 5 exemplifies pattern two of alters' religious affiliation in a network. The religion of the participant and the most frequent alter religion is protestant, represented by the lighter blue. The dark blue denotes Roman Catholic, the orange Islam, the green Seventh Day Adventist and the yellow Jehovah's Witness. There are a total of 16 cliques in this network, all containing at least one protestant member and most formed of solely protestant members. 


\section{Figure 5}

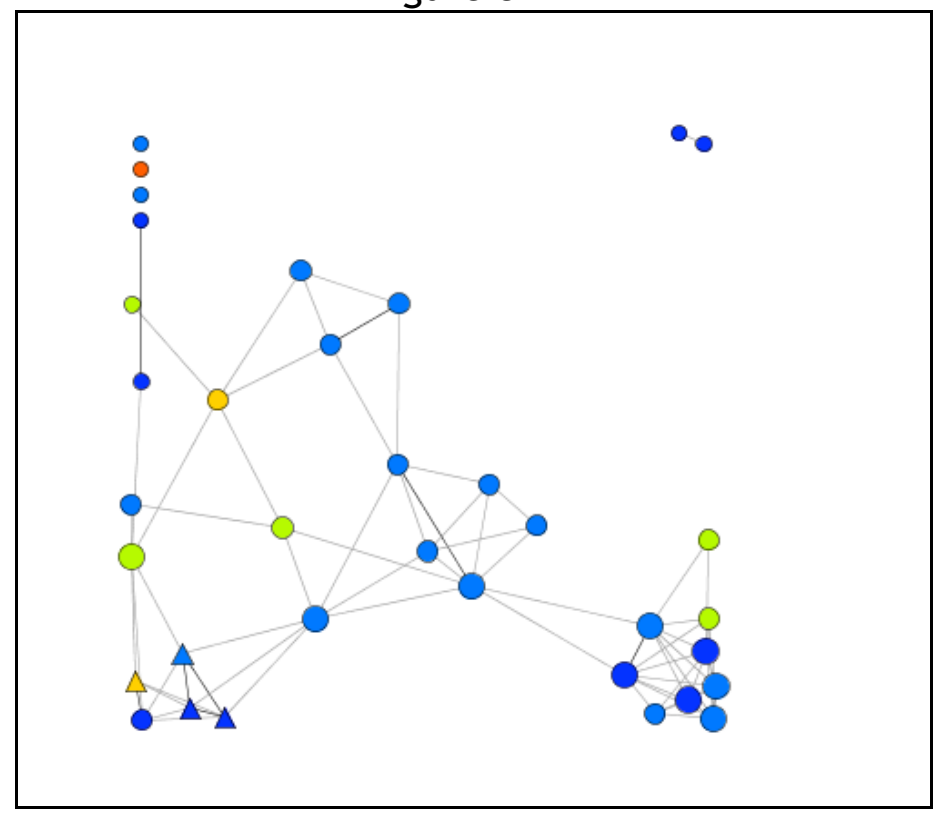

The third is a network that contains alters of the same religion as the participant dispersed throughout the network with no clear pattern, but a clear dominance of the network. This third form is similar to the second in that there are often numerous cliques dominated by members of the religious affiliation of the participant. However, it should be seen as a separate form, because of the clear domination and inclusion of members of this religion in the entire network. The third image below exemplifies this type of network. The dark blue represents Roman Catholicism and the religion of the participant. While the green and light blue represent Seventh Day Adventist and Protestant respectively. This network is composed of 61 cliques and three components. All dominated by the religion of the participant. 
Figure 6

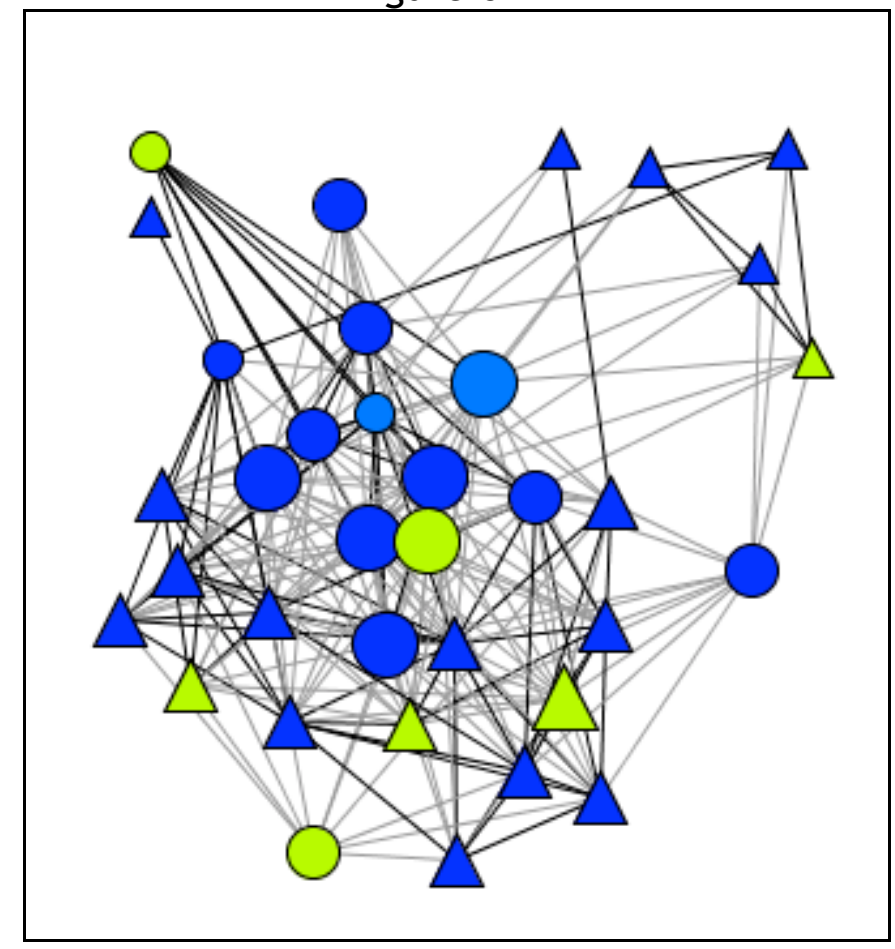

Religious affiliation acts as a determining factor for the formation of participants' social networks. The degree centrality of alters of the same religion of the participant for all three examples, and the entire sample, tends to be high. Additionally, Islamic participants tend to have male alters as more central figures within their networks, while members of other religious denominations often have more central female figures.

\begin{tabular}{|l|}
\hline \multicolumn{1}{|c|}{ Key For Figures 4-6 } \\
\hline \hline$\Delta=$ Male \\
$=$ Female \\
Orange $=$ Muslim \\
Dark Blue $=$ Roman Catholic \\
Light Blue = Protestant \\
Pink = Unsure \\
Green = Seventh Day Adventist \\
Yellow = Jehovah's Witness \\
\end{tabular}




\section{Discussion}

Women lacking male kin, an important resource within a social network in Rwanda, must gain support from other sources. The two most notable institutions through which women within this study gained support, apart from their kinship system, are women's organizations and religious affiliations. Each of the women in this study was able to name 35 people with whom she had contact during the past two years. A higher proportion of women $21(72 \%)$ stated they relied more heavily on their connections through women's organizations than their kinship ties. Thirteen women (87\%) out of the 15 women composing the older cohort stated they relied more heavily on their connections through women's organizations than any other institution, including kin. While nine (64\%) out of the 14 women composing the younger cohort stated they relied more heavily on their connections through women's organizations than any other institution, including kin. Quantitative data shows women's organization members consistently offering support at a 3 or 4 on the likert scale, thus supporting this assertion. The high degrees of support shared between alters who are members of a women's organization supports this assertion.

In the qualitative data, the concepts of development, progress or a better future for one's family and children as well as self betterment appeared in all 29 qualitative interviews. Women often made statements about "developing themselves" through participation in cooperatives and often other occupations. Many women stated they wanted their children to have an education which they believed would lead to more monetary and physical resources. Self betterment appeared in the forms of practical betterment such as learning a trade or gaining property as well as emotional betterment and healing from loss. Women made statements about "gaining capital," 
"working to have a better life" and "providing for [their] children's education". Older women professed goals of bettering the lives of their children and preparing for old age and retirement, while younger women aspired to marry and have a family as well as to provide for the future of that family. The presence of international aid organizations resonates through Rwandan women's sentiments about the importance of their women's organization and the progress they are making.

Through the data analysis, it became clear that an additional social institution, religion, was also bolstering the social networks of Rwandan women from either cohort. Across the sample, alters provided support scoring either a three or a four on the scale 75 percent of the time. In other words, three quarters of the 1,015 alters provided high levels of support to their corresponding participant. The hypothesis of this study argued women in the older cohort would depend more heavily on their connections through women's organizations than women from the younger cohort. Women from the older cohort demonstrated a slightly higher frequency of dependence on alters who held membership in a women's organization. Women from both subsamples stated they received high levels of support from members of women's organizations. A strong proportion of participants placed their dependence on women's organization members above their dependence on kinship ties. Additionally, the high level of involvement and integration of women's organizations into the networks of the younger cohort likely resulted in part from the strong fetishization of women in development by the international aid community (Autesserre 2010; Escobar 1995). Younger cohort members consistently proclaimed sentiments of personal and communal development during the qualitative portion of the interview. Younger cohort study participants also appeared to view women's organizations as a means to enhance their resumes, provide travel opportunities and lead to occupational advancement. 
In addition to women's organizations, the data demonstrated high levels of dependence on alters of the same religious affiliation. While the hypothesis for this study was somewhat true, it failed to capture the entire truth of the situation. Women with depleted kinship networks do appear to supplement their networks with members of women's organizations; however, they also appear to use religious affiliation for the same purpose. In all but three instances participants maintained the same religious affiliation as the highest proportion of their alters. In one instance the participant was Roman Catholic and the highest proportion of her alters was protestant, however, there was only one more protestant alter than the number of catholic alters. In the other two instances the participant practiced another religion aside from Catholicism and the highest proportion of their alters were Roman Catholic. High numbers of Roman Catholic alters in the network of a non-Catholic participant likely arises from the strong majority of the population Roman Catholicism encompasses.

Qualitative interviews reveal themes of need, dependence, education, survival, social gain and development as strong motivations for membership in women's organizations. Women expressed material need as well as the need for counseling and services, such as legal aid. Many women expressed a level of dependence on their organization for trade training and resources, seating the organization at a high level of importance for survival. Participants were very interested in providing for the education of their children so they may rise in social status and develop themselves. However, in the women's organizations with religious affiliations there was also a strong sense of unity lacking in the some of the organizations aimed at addressing practical needs, such as legal aid. Themes of solidarity were also present in secular organizations such as AVEGA due to beneficiaries' ability to empathize with the situations of their fellow widows. International aid agencies should aim to develop programs that cultivate emotionally charged 
relationships between their members, wherein women can develop unity and solidarity as a group.

Social networks often exhibit a high degree of "homophily by gender," or alters of the same gender as ego are overrepresented relative to alters of other genders (Roberts, Dunbar, Pollet and Kuppens 2009:138). Both cohorts are subject to this common trait of networks as shown in Table 10 which shows the percentage of social networks with a majority of alters of either gender. Some of the homophily by gender may result from Rwandan culture, which privileges homosocial groups, meaning that women associate with women and men associate with men. However, another explanation is also possible. While networks tend to be dominated by alters of the same gender as the ego, the high degrees of female majority within these networks may demonstrate a lack of males with which to associate. In the few networks that were male dominated majority was only achieved marginally, while female dominated networks tend to have a significant majority of female alters. As mentioned previously, the 1994 genocide led to significant population loss in Rwanda. Men tend to die at higher rates in situations of armed conflict than women or children because of the structure of armed conflicts (Ormhaug 2009). Additionally, nearly all of the individuals on trial by the International Criminal Tribunal for Rwanda, the court established to seek justice for the genocide, are male. Rwandan women may associate with males less frequently than women in part because men are missing because of the events of 1994. 


\begin{tabular}{|l|l|l|l|}
\hline \multicolumn{3}{|c|}{ Table- 11 Participants with Networks Composed of a Majority of Alters of Either } \\
\hline & Total N (\%) & Older Cohort N (\%) & Younger Cohort N (\%) \\
\hline $\begin{array}{l}\text { Male Majority } \\
\text { Networks }\end{array}$ & $3(10 \%)$ & $2(13 \%)$ & $1(7 \%)$ \\
\hline $\begin{array}{l}\text { Female } \\
\text { Majority } \\
\text { Networks }\end{array}$ & $26(90 \%)$ & $13(87 \%)$ & $13(93 \%)$ \\
\hline
\end{tabular}

\section{Conclusion}

Large scale and interpersonal gendered power relations impact the life courses of Rwandan women. Individuals occupy "social space” wherein "objective power relations" are imposed upon the agency of humans limiting their choices in action (Bourdieu 2012[1984]:666). Power structures are created through the use and reification of "cultural capital," or various qualities assigned to individuals or groups within society that allot them power and prestige over other groups and individuals (Bourdieu 2012[1984]:666). Rwandan women experience constraints on their ability to obtain cultural capital because of their nationality, gender, class, and other social identifiers such as race or presumed perpetrator status. International aid agencies appear to apply Westernized notions of womanhood, success, growth and desire to the women of Rwanda in their efforts to develop the country and the women's movement. This will have limited beneficial outcomes and detrimentally impacts Rwandan women by seating them further within what Patricia Hill-Collins calls a "matrix of domination" (Hill-Collins 2012[2000]:574). Hill-Collins 2012[2000] posits individuals' positions within any society result from "multiple contiguous standpoints" not an "essentialist standpoint" (574). The position of Rwandan women results from their simultaneous oppression and aid by various groups such as international feminists and the government. Arguably women receive assistance from these institutions in the form of efforts for more political offices to be held by women and other such endeavors. 
However, the practical reality of the situation of Rwandan women today is one limited by their gender as well as their nationality. This explanation lacks accuracy as well however, because it treats Rwandan women as a homogenous group that shares goals, aspirations and values.

Rwandan women's desires are shaped by their cultural experiences as Rwandans, but they are also shaped by the cultural experiences that they have as members of social classes, religions, and other distinct sub-cultures. The historical traditions of women in Rwanda may similarly fall along their nationality, their religion, their region of the country, their family history and various other identifiers, allowing for variation between women. State agendas do not impact all Rwandan women in the same way; the impact of state efforts to maintain ethnic divisions along the lines of victim and perpetrator, leads to very different outcomes for Hutu and Tutsi women for example. Finally, individuals possess agency, however constrained, determined in part by their past decisions.

There are several notable limitations to this study. First, the small sample size (29 participants) limits the generalizability of the results. Second, the short period during which fieldwork was conducted (4 weeks) prohibits participant observation as an effective method of research and limits the scope of the study. Conducting participant observation would have added objective observational depth to the study, which could bolster or contradict self-report interview data. Third, because interviews were generally conducted during normal business hours, participants were commonly unemployed, adding bias to the data. Acknowledging the aforementioned limitations this project adds to academic conversations regarding social network analysis as well as post genocide gendered insecurities and activism. Previous studies (Tucker, Kennedy, Ryan, Wenzel, Golinelli and Zazzali 2009) utilized social network analysis to study homeless women's networks. Helms 2003 conducted research on Bosnian women's social 
activism following the cessation of the genocide in the early 1990s. Much of the methodology for my study resembles that of Tucker et al. 2009, while the subject matter overlaps extensively with Helms 2003. Tucker et al. 2009 focuses on 30 women's relationships with alters through risk behavior. The organization of the study was used for a model for the execution of this study. The information gleaned from the conclusion of this study can add to the conversation begun by Helms 2003 about the importance of women's activism following periods of serious and widespread female victimization.

Women's organizations within Rwanda today emerged largely out of necessity and appropriate conditions for their support and endurance. Had the international community not fetishized global feminism and the Rwandan government not aimed to please the international community while women were socially vulnerable, women's organizations may not have developed their current strength. Women's organizations in Rwanda are both influenced by Western power dynamics, through economic attachments, and separate from Western notions of feminism. The position of Rwandan women's organizations relative to women within Rwanda, the broader Rwandan community, the international feminist community and the international development community remains convoluted. The international aid community should seek to provide aid that directly applies to the situation within Rwanda and the goals and desires of women.

The aid community should not graft foreign notions of equality into the structures of women's organizations but rather support and cultivate those that already exist. Aid agencies cannot successfully implement changes for gender equality from the highest levels while neglecting local level populations (Autesserre 2010; Escobar 1995). Should the right pursuits, including equal access to education, politics, the economy and market, as well as other forms of 
social leadership and agency, gain government and international attention women's organizations may obtain a larger degree of equality for women within Rwanda. Additionally, acknowledging the central importance of religious organizations in the lives of women is necessary for appropriate tactics for development.

The role religious affiliation plays in the formation of women's networks and their receipt of support requires attention. Those interested in the development of women and pursuit of gender equality should consider this connection when developing programs. Secularism in social change organizations may have merit in the Western world more so than in Rwanda. While religion remains such a key component of the lives of Rwandan women it should be incorporated as a key component of the movement for gender equality. Rwandan women's social networks demonstrate which institutions hold prominence socially and therefore maintain influential power. The difference in dependence for support the two cohorts held less significance than hypothesized potentially due to growing power and prominence of women's organizations in Rwanda. This assertion requires further research to confirm or disprove. Both cohorts also maintained strong dependence on their perspective religious organizations. Rwandan women similarly to rhizomes with no clear bounds of allegiance to feminism or religion exclusively (Deleuze and Guattari 1987). They appear to structure their lives in a way that permits the maintenance of traditional social institutions (religion) and progressive social movements for gender equality. This supports Sherine Hafez's assertion about Muslim women's activists operating between the religious and secular communities (2011). Hafez (2011) posits Muslim women operate as feminist activists and practitioners of faith simultaneously, negotiating their relationship with their faith to fit into their activist efforts. Rwandan women's location between religion and social development will likely appear in other areas of the world. 
Those cultures that contain strong traditional institutions such as, but not necessarily limited to, religion will likely experience activism in similar ways. The case of Rwandan however, remains unique because of the historically recent turmoil and violence. Countries containing the generation present during conflict within their populous should show the highest degree of similarity to the Rwandan case. 


\section{Bibliography}

Autesserre, Severine

2010. The Trouble with the Congo: Local Violence and the Failure of International

Peacebuilding. Cambridge: Cambridge University Press.

Benedict, Ruth

2010 [1934] The Individual and the Pattern of Culture In Erickson, Paul A. and Murphy, Liam D. eds., Readings for a History of Anthropological Theory. Pp 147-160. University of Toronto Press.

Burnet, Jennie E.

2012 Genocide Lives in Us: Women, Memory and Silence in Rwanda. Wisconsin: The University of Wisconsin Press.

Burnet, Jennie E.

2009. Whose Genocide? Whose Truth? Representations of victim and perpetrator in Rwanda. In Genocide: Truth, Memory and Representation. A.L. Hinton and K. O’Neill, eds. Pp. 80110. Durham: Duke University Press.

Burnet, Jennie E.

2008 Gender Balance and The Meanings of Women In Governance In Post-Genocide Rwanda. Oxford University Press.

Butler, Judith

1997 [1993 Excerpt from "Introduction" to Bodies That Matter. In The gender/sexuality reader:culture, history, political economy. R.N. Lancaster and M. Di Leonardo, eds. Pp. 531-542. New York: Routledge.

Butler, Judith

1999 Subjects of Sex / Gender / Desire In Gender trouble: feminism and the subversion of identity. J. Butler, ed. Pp. 3-11. New York: Routledge.

Chambers, Clare

2008 Sex, Culture and Justice: The Limits of Choice. University Park Pennsylvania. Pennsylvania State University Press.

Cohen, Mardge H., d'Adesky, Anne-Christine, and Anastos, Kathryn 2005 Women in Rwanda: Another World is Possible.

De Lame, Danielle 2005 A Hill Among a Thousand. Madison: Wisconsin. The University of Wisconsin Press. 
Deleuze, Gilles and Guattari, Felix

1987 A Thousand Plateaus. Minneapolis: Minnesota. University of Minnesota Press.

Eltringham, Nigel

2006 'Invaders who have stolen the country': The Hamitic Hypothesis, Race and the Rwandan Genocide In Social Identities 12:4:425-446. Routledge: Taylor \& Francis.

Escobar, Arturo

1995 Encountering Development: The making and Unmaking of the Third World. Princeton University Press.

Evans, Judith

1995 Feminist Theory Today: An Introduction to Second-Wave Feminism. London: Sage Publications.

Ferguson, James

1997 Anthropology and its Evil Twin: "Development" in the Constitution of an In International Development and the Social Sciences: Essays on History and Politics of Knowledge. Pp. 150-175. Berkeley: University of California Press.

Gilman, Charlotte Perkins

2012 Women and Economics In Classical and Contemporary Sociological Theory: Text and Readings. Sage Publishers: Los Angeles.

Handrahan, Lori

2004 Conflict, Gender, Ethnicity and Post-Conflict Reconstruction. Sage Publications.

Hafez, Sherine

2011 An Islam of Her Own: Reconsidering Religion and Secularism in Women's Islamic Movements. New York and London: New York University Press.

Helms, Elissa

2003 Gendered Visions Of The Bosnian Future:Women's Activism And Representation In

Post- War Bosnia-Herzegovina. University of Pittsburg.

Hill-Collins, Patricia

2012 [1990] Black Feminist Thought In Classical and Contemporary Sociological Theory: Text and Readings. Sage Publishers: Los Angeles.

Kleinman, Sherryl 2007 Why Sexist Language Matters In The Center Line. Orange County Rape Crisis Center.

Kumar, Krishna 
2001 Civil Wars, Women, and Gender Relations: An Overview In Women and Civil War: Impact, Organizations and Action. Ed. Krishna Kumar. Boulder Colorado: Lynne Rienner Publishers Inc.

Kumar, Krishna

2001 International Assistance to Women's Organizations In Women and Civil War: Impact, Organizations and Action. Ed. Krishna Kumar. Boulder Colorado: Lynne Rienner Publishers Inc.

Lazarus-Black, Mindie

2007. Everyday Harm: Domestic Violence, Court Rites, and Cultures of Reconciliation. University of Illinois Press.

Lemarchand, Rene 2010 The Dynamics of Violence in Central Africa. University of Pennsylvania Press.

McIver, John P. and Carmines, Edward G.

1981 Unidimensional Scaling. Sage Publications Inc.

Mulcahy, Dianne and Perillo, Suzanne

2011Thinking Management and Leadership Within Colleges and Schools Somewhat Differently: A Practice-Based, Actor Network Theory Perspective. Educational Management Administration \& Leadership. Sage Publicaitons.

Merry, Sally Engle

2006. Human Rights \& Gender Violence: Translating International Law into Local Justice. The University of Chicago Press.

Newman, David M.

2007 Identities and Inequalities: Exploring the Intersections of Race, Class, Gender, and Sexuality. Boston: McGraw Hill.

Newbury, Catharine and Baldwin, Hannah

2001 Profile: Rwanda In Women and Civil War: Impact, Organizations and Action. Ed. Krishna Kumar. Boulder Colorado: Lynne Rienner Publishers Inc.

Newbury, Catharine and Baldwin, Hannah

2001 Confronting the Aftermath of Conflict: Women's Organizations in Postgenocide Rwanda In Women and Civil War: Impact, Organizations and Action. Ed. Krishna Kumar. Boulder Colorado: Lynne Rienner Publishers Inc.

Nugent, David

2002 Locating Capitalism in Time and Space: Global Restructurings, Politics, and Identity. Pp. 1-59. California: Stanford University Press. 
Ortner, Sherry B.

1974 Is Female to Male as Nature is to Culture? In Woman, culture, and society. M.Z.

Rosaldo, L. Lamphere, and J. Bamberger, eds. Pp. 67-88. Stanford, California: Stanford University Press.

Ormhaug, Christin 2009 Armed Conflict Deaths Disaggregated by Gender. International Peace Research Institute. Norwegian Ministry of Foreign Affairs.

Pottier, Johan

2002. Re-Imagining Rwanda: Conflict, Survical and Disinformation in the Late Twentieth Century. Cambridge University Press.

Radcliffe-Brown, Alfred R.

2010 [1958] Social Structure In Erickson, Paul A. and Murphy, Liam D. eds., Readings for a History of Anthropological Theory. Pp 196-201. University of Toronto Press.

Remmert, Consuelo

2003 Women in Reconstruction: Rwanda Promotes Women Decision-Makers. United Nations Chronicle No. 4.

Rich, Adrienne

1986 Notes toward a Politics of Location In Blood, Bread, and Poetry: Selected Prose 19791985, New York: W.W. Norton Co, 1986, pp. 210-217

Rivers, W.H.R

1900 A Genealogical Method of Collecting Social and Vital Statistics In The Journal of the Anthropological Institute of Great Britain and Ireland, Vol. 30 pp. 74-82. Royal Anthropological Institute of Great Britain and Ireland.

Saussure, Ferdinand De

2010 [1916] Nature of the Linguistic Sign and Synchronic and Diachronic Law In Erickson, Paul A. and Murphy, Liam D. eds., Readings for a History of Anthropological Theory. Pp 95100. University of Toronto Press.

Scott, John

2000. Social Network Analysis: A Handbook. Second Edition. Sage Publications.

Sommers, Marc

2012 Stuck: Rwandan Youth and the Struggle for Adulthood. Athens, GA: University of Georgia Press.

Straus, Scott and Waldorf Lars

2011. Remaking Rwanda: State Building and Human Rights after Mass Violence. The University of Wisconsin Press. 
Straus, Scott

2006 Background to Genocide. In The Order of Genocide: Race, Power, and War in Rwanda. S. Straus, ed. Pp. 17-40. Ithaca, New York: Cornell University Press.

Tucker, Joan S.; Kennedy, David; Ryan, Gery; Wenzel, Suzanne L.; Golinelli, Daniela; Zazzali, James. 2009. Homeless Women's Personal Networks: Implications for Understanding Risk Behavior In Human Organization, Vol. 60. No. 2. Pp129-140. Society for Applied Anthropology.

Tylor, Edward Burnett 2010 [1873] The Science of Culture In Erickson, Paul A. and Murphy, Liam D. eds., Readings for a History of Anthropological Theory. Pp 30-42. University of Toronto Press.

Uvin, Peter 2009 Life After Violence: A People’s Story of Burundi. Zed Books.

Uvin, Peter 1998 Aiding Violence: The Development of Enterprise in Rwanda. Kumarian Press.

Waldorf, Lars

2006 Mass Justice for Mass Atrocity: Rethinking Local Justice as Transitional Justice. Temple Law Review 79(1):1-87.

Wolf, Eric

1999 Envisioning Power: Ideologies of Dominance and Crisis. Berkeley: University of California Press. 